\title{
Transitions to adulthood in the context of AIDS in South Africa: The impact of exposure to life skills education on adolescent knowledge, skills, and behavior
}

The Transitions to Adulthood Study Team

Follow this and additional works at: https://knowledgecommons.popcouncil.org/departments_sbsr-hiv

Part of the Demography, Population, and Ecology Commons, Health Policy Commons, Immune System Diseases Commons, International Public Health Commons, Medicine and Health Commons, Public Health Education and Promotion Commons, and the Virus Diseases Commons How does access to this work benefit you? Let us know!

\section{Recommended Citation}

The Transitions to Adulthood Study Team. 2004. "Transitions to adulthood in the context of AIDS in South Africa: The impact of exposure to life skills education on adolescent knowledge, skills, and behavior," Horizons Final Report. Washington, DC: Population Council. 


\section{Hgrizons}

Transitions to Adulthood in the Context of AIDS in South Africa:

The Impact of Exposure to Life Skills Education on Adolescent Knowledge, Skills, and Behavior

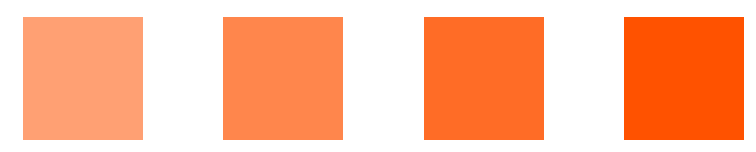

Horizons Program Tulane University University of Natal, Durban Population Council Development Research Africa 


\section{Transitions to Adulthood in the Context of AI DS in South Africa:}

\section{The I mpact of Exposure to Life Skills Education on Adolescent Knowledge, Skills, and Behavior}

The Transitions to Adulthood Study Team

With analysis performed by:

Robert Magnani,

Ali Mehyrar Karim,

Kate Macintyre,

Lisanne Brown, and

Paul Hutchinson 


\section{Acknowledgments}

"Transitions to Adulthood in the Context of AIDS in South Africa" is a collaborative research project of the University of Natal-Durban School of Development Studies, the Horizons Program and the Policy Research Division of the Population Council, and Tulane University School of Public Health \& Tropical Medicine under the auspices of the FOCUS on Young Adults and MEASURE/Evaluation Project. DRA Development carried out fieldwork for the Wave 1 and Wave 2 of data collection. Data entry and cleaning was carried out by Policy and Praxis for Wave 1 and by DRA Development for Wave 2.

First, we would like to thank the young South Africans who responded so willingly to the questionnaires in both 1999 and 2001. In addition, all those who conducted the interviews deserve a special thanks for their dedication and professionalism throughout the study period. Finally, we are grateful to those individuals who reviewed earlier drafts of this report, including Dr. Priscilla Reddy of the Medical Research Council -

Cape Town, Ann McCauley of Horizons/International Center for Research on Women, Nancy Murray of the Futures Group, and Quarraisha Abdool Karim of the Center for the Programme of Research in South Africa.

USAID This publication is made possible through support provided by the U. S. Agency for International Development through the Horizons Program (under the terms of Cooperative Agreement No. HRN-A-00-9700012-00), the FOCUS on Young Adults Project (Cooperative Agreement No. CCP-3-73-A00-6002-00), the VIIII MEASURE/Evaluation Project (Cooperative Agreement HRN-A-00-97-00018-00), and by a Rockefeller Foundation grant to the Population Council's Policy Research Division. The opinions expressed herein are those of the authors and do not necessarily reflect the views of the U.S. Agency for International Development or the Rockefeller Foundation.

Published in March 2004.

Horizons is implemented by the Population Council in collaboration with the International Center for Research on Women (ICRW), the International HIV/AIDS Alliance, the Program for Appropriate Technology in Health (PATH), Tulane University, Family Health International (FHI), and Johns Hopkins University.

\section{(2) Population Council}

The Population Council is an international, nonprofit, nongovernmental institution that seeks to improve the well-being and reproductive health of current and future generations around the world and to help achieve a humane, equitable, and sustainable balance between people and resources. The Council conducts biomedical, social science, and public health research and helps build research capacities in developing countries. Established in 1952, the Council is governed by an international board of trustees. Its New York headquarters supports a global network of regional and country offices.

This document may be reproduced in whole or in part without permission of the Population Council provided full source citation is given and the reproduction is not for commercial purposes.

Suggested citation: The Transitions to Adulthood Study Team. 2004. "Transitions to Adulthood in the Context of AIDS in South Africa: The Impact of Exposure to Life Skills Education on Adolescent Knowledge, Skills, and Behavior," Horizons Final Report. Washington, D.C.: Population Council. 


\section{The Transitions to Adulthood Study Team members are:}

$\underline{\text { University of Natal, Durban }}$

Julian May

Ntsiki Manzini

Population Council

Carol Kaufman (now with University of Colorado Health Sciences Center)

Naomi Rutenberg

Kelly Hallman

Tulane University

Lisanne Brown

Ali Mehyrar Karim

Bob Magnani

Kate Macintyre

Paul Hutchinson

DRA Development

Stavrou Stavros

Anthea Dallimore

Ruanne Fensham 



\section{Table of Contents}

Executive Summary

Introduction

\section{Background}

Youth, sex, and the South African context

Sex education and life skills programs: History and theoretical frameworks

The Transitions Study

Conceptual framework

Outcomes

\section{Data and Methods}

Study setting

Study design

Measurement and analysis

Exposure to life skills education

Changes in outcome indicators 
References

$\begin{array}{ll}\text { Appendix A } & 55\end{array}$ 


\section{Executive Summary}

In response to the escalating HIV/AIDS epidemic, in 1998 the South African Ministry of Education mandated that a comprehensive life skills education program be implemented in all secondary schools by 2005. Although it is too early to assess the long-term impact of this initiative, the phased implementation of the program provides an opportunity to assess short-term impact. This study measures the effects of exposure to topics within the life skills curriculum on sexual and reproductive health knowledge and behaviors among youth in KwaZulu Natal, during the 19992001 period.

The "Transitions" study is a prospective study of adolescents in KwaZulu Natal province that gathered data on sexual and reproductive health behaviors, education and employment experiences, family and environmental conditions, and other factors in their lives that may influence their sexual behavior and choices. One objective of the study was to contribute to our understanding of the effectiveness of life skills education in changing behavior.

\section{Study Site/ Sampling Design}

Two administrative areas in KwaZulu Natal, Durban Metro and Mtunzini Magisterial Districts, were purposively selected. Within each area, all youth 14-22 years of age residing in a segmented, probability sample of Census Enumeration Areas (CEAs) were interviewed in the Wave 1 survey (1999). In Wave 2 (2001), all youth 14-24 years of age residing in the same CEAs were included in the survey, including 2,222 of the 3,052 youth also interviewed in Wave 1 .

\section{Methods}

Because the South Africa life skills initiative aimed to be a full coverage program, it was not possible to use a randomized control design to measure program impact. This is because schools initiated or developed life skills education at different speeds and intensities. The study therefore measured young people's recall of 11 topics from their school training, and assessed the differences in sexual and reproductive health knowledge and behaviors, given that these young people were differentially exposed to the topics. This is called measuring the dose-response relationship between indicators of exposure to education and sexual and reproductive health knowledge and behaviors. All the multivariate models control for unmeasured factors using a variable for survey year. A significant effect for this survey year variable was found for many of the models and may be interpreted as reflecting the combined effects of maturation of youth, exposure to other sources of information other than life skills education, and general secular trends. Exposure to life skills education was measured by changes in recall of 11 key sexual-reproductive health topics based upon student report. Outcomes included: 1) sexual abstinence to either postpone first sex (delay initiation), or for those already initiated to reduce risk through secondary abstinence; 2) reduced number of sex partners in the past 12 months; and 3) changes in condom use (i.e. condom use at 


\section{Hgrizons}

first sex; condom use at last sex and consistency of condom use with all partners). Separate analyses were conducted by sex, race, and age.

\section{Intervention}

In November 1995, the Department of Health and Department of Education formed the National Coordinating Committee for Life Skills and HIV/AIDS. The committee gave high priority to establishing a life skills/HIV education course in secondary schools and planned for the course to be nationwide by January 1998 and fully implemented by 2005. The goal was to increase knowledge, develop skills, promote positive and responsible attitudes, and provide motivational support (South African Departments of Health and Education 1997/98). As a result of exposure to the program, students are expected to be able to: (1) demonstrate a clear and accurate understanding of sex, sexuality, gender, and STIs, (2) critically identify ways in which HIV/STIs can and cannot be transmitted, (3) identify and evaluate the effectiveness of HIV/STI prevention methods, (4) identify, access, and mobilize sources of assistance within a community, (5) critically evaluate reasons for delaying sexual intercourse or practicing abstinence, (6) respond assertively to pressure for sexual intercourse and unprotected sex, (7) critically evaluate reasons and methods for having protected sex when/if sexually active, (8) accept, cope, and live positively with the knowledge of being HIV positive, (9) show compassion and solidarity towards persons with HIV/AIDS and those affected, (10) provide basic care for people living with HIV and AIDS in the family and community, and (11) understand and cope with loss and the grieving process.

\section{Key Findings}

\section{Exposure to life skills education}

Students report a substantial increase in exposure to life skills over the two-year period of this study. By 2001, most students reported being exposed to at least some life skills education to help them reduce their risk of STI/HIV infection. The largest gains in exposure were observed among African and Indian students.

\section{Knowledge}

Gains in sexual and reproductive health knowledge generally were modest in magnitude and uneven across topics, although substantial gains were noted on a number of key topics for HIV prevention. For youth in the aggregate, significant effects of exposure to life skills education are observed for three knowledge outcomes: knowledge of modes of HIV transmission, knowledge of STIs other than HIV, and number of contraceptive methods known. In general, where significant effects were observed, the effects are more consistent for males than females, for Africans vs. youth of other races, and for younger vs. older youth. 


\section{Behaviors}

Youth exposed to life skills education are more likely to use condoms, but there was no effect on other key behaviors, such as delaying sexual initiation or reducing their number of partners in the last 12 months.

- Exposure to life skills education showed an effect on confidence to obtain condoms among females, Africans, and 19-22 year-olds. For the self-efficacy of condom use outcome, exposure effects are widespread across most sub-groups of youth.

- Overall, those exposed to life skills education were significantly more likely to show an increase in reported condom use at first sex and last sex. Females, Africans, and younger youth exposed to the program were more likely to report condom use at first sex. Africans and younger youth were more likely to report condom use at last sex.

- Although there are modest increases in secondary abstinence and the number of partners reported in the last 12 months at the bivariate level, the results showed no impact on these behaviors among those exposed to life skills. However, the survey year effect was significant and positive, suggesting that the increased prevalence of secondary abstinence and number of partners reported in the last 12 months was due to influences other than school-based life skills education.

\section{Conclusions and Program I mplications}

The findings indicate substantial short-to-medium- term effects of exposure to life skills education on certain areas of sexual and reproductive health-related knowledge, confidence to use condoms, and condom use behavior. However, no effects on age at sexual debut or partner reduction were observed. Despite significant increases in condom use at last sex, these levels are only moderate (less than 60 percent for those reporting sexual activity), thus many youth remain at high risk. Further research is needed to assess whether the observed effects are transitory or long-term in nature, whether the observed behavioral changes have an impact on HIV infection rates among youth, and whether the full implementation of life skills education in all schools in KwaZulu Natal can broaden program impact to also include other sexual behaviors such as delay of sexual initiation and secondary abstinence. The results of this study have a number of implications for the provision of life skills education in South Africa.

- Knowledge of reproductive health, STIs, and HIV is generally good, but could be improved. While almost all respondents were aware of modes of transmission and prevention, many gaps in knowledge remain, in particular sharing of needles and other unclean instruments and mother-to-child transmission.

- Life skills education should equally emphasize all methods of preventing pregnancy and transmission of STIs and HIV. The results of this study suggest that students who were exposed to life skills education have increased their use of condoms, but there was no impact of exposure on other sexual behaviors such as age at sexual initiation, abstinence, and number of partners. This may be because the condom use messages are the only ones that students 


\section{Hgrizons}

retain or because life skills education is focusing more on condom use and less on other means of preventing pregnancy, STIs, and HIV.

- Life skills education should support secondary abstinence, which is already increasing due to other factors. The results show that secondary abstinence increased during the study time period. However, this change was not attributable to exposure to life skills education. Youth appear to be practicing secondary abstinence in response to other messages or changes in society, and the Life Skills Programme should help reinforce those changes.

- The gap in exposure to life skills education among the different racial groups needs to be further narrowed. In particular, life skills education for black populations needs to be strengthened. While this study shows significant improvement in this area over the two years of the study, the gap persists.

- Life skills education should be tailored to the needs of different groups. This study revealed important differences in sexual behaviors by age, sex, and population group. To the extent possible, life skills education should provide appropriate knowledge and skills to these different groups. 


\section{Introduction}

Youth in South Africa have been disproportionately affected by the HIV/AIDS epidemic. Although having less than 1 percent of the world's 15-24 year-olds, South Africa accounts for roughly 15 percent of all HIV infections globally in this age group (UNICEF, UNAIDS, and WHO 2002). The acceleration of the South African epidemic for this age group has been truly alarming. According to 1994 antenatal surveillance data, 7 percent of 15-19 year olds were HIV positive, a figure that rose to 22 percent by 1998 (Department of Health 2002). Estimates for 1999 and 2001 reveal declining prevalence levels for 15-19 year-olds (16.5 percent and 15.4 percent, respectively). In KwaZulu Natal Province (KZN), the site for the present study, prevalence among pregnant women escalated from 2 percent in 1990 to a high of 36 percent in 2000 before falling slightly to 34 percent in 2001 (Department of Health 2002). Data from a population survey conducted in 2002 indicate somewhat lower prevalence- -9.3 percent of $15-24$ year-olds nationally (12.0 percent of females and 6.1 percent of males) and 8.3 percent in KZN (Mandela Foundation and HSRC 2003). While not as alarming as the antenatal sentinel surveillance estimates, these data nevertheless indicate a significant generalized epidemic among South African youth.

The South African government's response to the epidemic has been erratic, but one major effort has been to develop a policy on the provision of life skills and HIV/AIDS education in secondary (and subsequently middle) schools. In 1995 the Departments of Health and Education, building upon the Children's Rights Charter of South Africa (1992), formed the National Coordinating Committee for Life Skills and HIV/AIDS, which gave highest priority to establishing a life skills and HIV education course in secondary schools, planning for it to be developed by January 1998 and fully implemented by 2005 (Department of Health and Department of Education 1998). Life skills education was conceptualized as "the formalized teaching of requisite skills for surviving, living with others and succeeding in a complex society." The formal goal of the Life Skills and HIV/AIDS Education Learning Programme for Grades 8-12 was to increase knowledge, develop skills, promote positive and responsible attitudes, and provide motivational supports. However, because of the HIV/AIDS crisis, it focused on a range of specific coping mechanisms. The curriculum was informed by classic cognitive and behavioral theoretical frameworks that have primarily informed western and other international approaches to sex education over the past decade (Moote and Wodarski 1997; PAHO 2001).

The National Project Committee oversaw curriculum development and issued implementation guidelines, but each province was responsible for designing and implementing its own program, assisted by relevant national directorates (e.g., the National AIDS Program). Inevitably, provinces

have implemented life skills curricula at different speeds, modalities, and intensities. Data from the Transitions study showed that in Durban Metro only about 15 percent of secondary schools had fully implemented the province's program, including formal adoption of the "official" curricula and teacher training, by the end of 1999 (Brown et al. 2003). However, nearly all schools had implemented some form of life skills education by 2001 in accordance with national policy, but coverage of the key topics (as reported/remembered by the students) varied and continues to vary 


\section{Hgrizons}

considerably, as does the type and timing of training of teachers, type of materials available to students, and the pedagogical methods used to give students the necessary information.

In this report we present findings on the effects of exposure to life skills education based on student recall of 11 life skills topics on sexual and reproductive health and HIV/AIDS-related knowledge, attitudes, and behaviors of adolescents in selected areas of KwaZulu Natal. This analysis was part of a major initiative led by the Horizons Program, in collaboration with other partners, to conduct a panel survey of young people in KZN in 1999 and 2001. Although school-based life skills education is a key component of the government of South Africa's HIV/AIDS prevention strategy, existing research from various parts of the world indicates at best mixed success of school-based programs in influencing sexual risk-taking and health-seeking behaviors among youth. A recent review of developing country programs indicates that school-based sexual and reproductive health educational efforts have failed as often as they have been successful in influencing youth sexual risk-taking behaviors (Speizer, Magnani, and Colvin: In Press), and a report by ActionAid concluded that school-based HIV/AIDS prevention programs are failing students in Africa and Asia (Boler 2003). These observations are consistent with reviews of meticulously evaluated school-based programs in the U.S. and Canada that concluded that only a minority of programs have been able to demonstrate behavioral impact (Kirby 1999; DiCenso et al. 2002), although Kirby (2001) observes that more recent initiatives that include an HIV prevention component appear to be more successful than earlier programs focused on pregnancy prevention.

This report therefore provides an important contribution to the existing literature on the effects of exposure to life skills education among youth in South Africa, one of the countries hardest hit by the HIV/AIDS epidemic. 


\section{Background}

\section{Youth, Sex, and the South African Context}

Societal transformations in South Africa and elsewhere have contributed to a lengthening of the period between puberty and marriage, particularly for girls; an increase in the number and nature of contacts by adolescents; and greater opportunities and potential for youth to extend their education and skills development (Bongaarts and Cohen 1998; Mensch, Bruce and Greene 1998; Caldwell et al.1998). These changes have increased adolescents' exposure to pre-marital and unsanctioned sexual activity with all its attendant health and social consequences (Blanc and Way 1998; Zabin and Kiragu 1998).

In the aftermath of apartheid, many South African youth were assumed to be on a path of increased economic and social opportunities. However, these opportunities are threatened by an HIV/AIDS epidemic fueled by high levels of unprotected sexual intercourse among youth. South Africa has one of the highest HIV infection rates in the world, and the prevalence of the disease among South African youth is particularly alarming. Moreover, while South Africa's total fertility rate is estimated to be one of the lowest in sub-Saharan Africa (2.9 nationally in 1998), levels of adolescent childbearing are very high-35 percent of 19 year olds have been pregnant (MRC and Macro International 1998).

The reproductive behavior of today's youth is not only a concern because of the social, economic and personal costs associated with early sexual childbearing, but also because it will likely shape the trajectory and impact of the AIDS epidemic for future generations.

\section{Sex Education and Life Skills Programs: History and Theoretical Frameworks}

A recent review of the evidence on sexual risk taking among adolescents in the United States concluded that such behaviors are affected by a large number of risk and protective factors that involve their partners, friends, families, and communities (Kirby 1999). These factors include sexual beliefs and skills as well as a broad array of social and economic influences, including poverty and social disorganization, which condition youth's choices, actions, and outcomes. Findings on the effectiveness of programs or interventions aimed at reducing the prevalence of adverse adolescent reproductive health outcomes in the U.S. strongly suggest that programs that attempt to influence the context in which youth live in addition to addressing reproductive health needs tend to be more effective than those that focus more narrowly on reproductive health knowledge and/or access to contraceptive/reproductive health services (Kirby 2001).

The history of South Africa has, like every other aspect of social life, affected sex education and guidance in the apartheid years (Richter 1996; Thompson 1990). For example, in most of Zulu land the school-based sexuality education was considered the domain of school nurses and local clinic 


\section{Hgrizons}

staff, and under-resourced schools often couldn't afford to pay for these services on a regular basis, if at all (Wilson and Ramphele 1989). There was no set curriculum in most schools. An even more negative influence on this region's schooling policies was that school attendance itself was not compulsory for Africans as recently as the late 1980's (Thompson 1990). Given these challenges, among many others, sexual and reproductive health education, or even any intention by policy makers to change this situation, was sorely lacking up to the early 1990's (National Education Conference 1992).

The legal framework that justified and stressed the need for children to have education on a broad range of life skills was encoded in the Children's Rights Charter of South Africa, where article 8 states: "all children have the right to education on issues such as sexuality, AIDS, human rights and family life" (Children's Rights Charter of South Africa 1992). There was agreement across new ministries (established post 1994) that children should be empowered with knowledge and skills to make informed decisions about their own sexual attitudes, beliefs, and behaviors.

The first major educational reform policy emphasized secondary education levels, with the aim of completely restructuring educational transformation and curriculum evaluation by 2005 . The subject of life skills training was defined as "the formalized teaching of requisite skills for surviving, living with others and succeeding in a complex society." However, as the life skills curriculum has been developed its focus has, because of AIDS, targeted a range of coping skills, including communication skills to negotiate, refuse or postpone sex; analytical skills to understand HIV/STI transmission, assess and access contraception (including finding and using condoms), recognize and seek treatment for STI symptoms; and caregiving skills to be able to look after friends or family with HIV-related illnesses. Much of the life skills portion of the curriculum was developed based on classic cognitive and behavioral theoretical frameworks that have informed many western and other international approaches to sex education over the past decade (Moote and Wodarski 1997; UNICEF/EASARO 1996). Box 1 summarizes the goal, theories that informed the development of the program, and the student learning objectives. However, it must be recognized that the training and implementation of life skills curricula at the school level, despite national and provincial guidelines, vary according to who provides funding and teacher training, what the school principal or the board is willing to accept or implement, the resources available for training and a host of other factors related to the level of willingness and commitment of the teachers to make time to teach these subjects to their students. 


\section{Box 1 The South Africa Life Skills Programme}

Policy: In November 1995, the Department of Health and Department of Education formed the National Coordinating Committee for Life Skills and HIV/AIDS. The committee gave high priority to establishing a life skills/HIV education course in secondary schools and planned for the course to be nationwide by January 1998 and fully implemented by 2005 .

Theoretical frameworks: The course was informed by the Children's Rights Charter of South Africa and cognitive and behavioral social-physiological theories. The acquisition of life skills was to be transmitted through learner-centered methods, including participatory learning, role models, peer education methods, and more formal structured lectures. Life skills is not an examinable subject in the public schools.

Goal: To increase knowledge, develop skills, promote positive and responsible attitudes, and provide motivational supports (Departments of Health and Education 1997/98).

Learning objectives: As a result of exposure to the program, students are expected to be able to:

- Demonstrate a clear and accurate understanding of sex, sexuality, gender, and STIs.

- Critically identify ways in which HIV/STIs can and cannot be transmitted.

- Identify and evaluate the effectiveness of HIV/STI prevention methods.

- Identify, access, and mobilize sources of assistance within a community.

- Critically evaluate reasons for delaying sexual intercourse or practicing abstinence.

- Respond assertively to pressures for sexual intercourse and unprotected sex.

- Critically evaluate reasons and methods for having protected sex when/if sexually active.

- Accept, cope, and live positively with the knowledge of being HIV positive.

- Show compassion and solidarity towards persons with HIV/AIDS and those affected.

- Be able to provide basic care for people living with HIV/AIDS in the family and community.

- Understand and cope with loss and the grieving process.

Although the life skills component of the secondary education program is a key element in the government of South Africa's response to the epidemic, we know little about the impact of exposure to life skills education or the way in which it combines with other resources of families and/or communities to influence youth behavior. Indeed, recent reviews of school-based programs in both developed and developing countries, many comparable in design to the South African Life Skills Programme, indicate mixed results (Kirby 2001; DiCenso et al. 2002; Speizer, Magnani, and Colvin 2003). While some success has been realized, many programs have failed to demonstrate behavioral impact. 


\section{Hgrizons}

\section{The Transitions Study}

Transitions to Adulthood in the Context of AIDS in South Africa is a prospective, panel study of sexual and reproductive health behaviors and outcomes among adolescents in selected areas of KZN province. The study also examines their education and employment experiences, family and environmental conditions, and other factors in their lives that may influence their sexual behavior and choices. The Transitions study was designed to make an important contribution to our understanding of how life skills education works and its effectiveness in changing the behavior of students.

The Transitions study's main objective was to investigate the impact of life skills education and other programs on adolescents' understanding of HIV/STI transmission and personal risks, attitudes towards persons living with HIV/AIDS, and risk-taking and health seeking behaviors, especially those behaviors associated with the spread of HIV and other STIs.

\section{Conceptual Framework}

The conceptual framework illustrated in Figure 1 was developed from an extensive analysis of both global and South African literature on the risk and protective factors that increase or decrease young peoples' exposure to poor reproductive health outcomes. The figure shows the interrelatedness of adolescent, family, and community life. Individuals exert influence on the families with whom they reside, just as families shape the characteristics of individual family members. Analogously, a community may have particular characteristics that influence family or household decisions, while individual households also contribute to the neighborhood environment. We posit that although the effects are not uni-directional, the influence of families and communities works through individual-level characteristics of adolescents to shape reproductive health outcomes and key experiences in adolescence, such as the pace and progress through school, or age at sexual initiation.

Of interest for this report, the figure also includes the impact of life skills education, which we treat as exogenous or independent of the characteristics of adolescents. While characteristics of adolescents will have a direct effect on the outcomes of interest to the study, we hypothesize that life skills education will mediate that relationship. The effect of the mediation will depend on a number of factors, among them the content of life skills education. 
Figure 1 Conceptual framework: Transitions to adulthood in South Africa

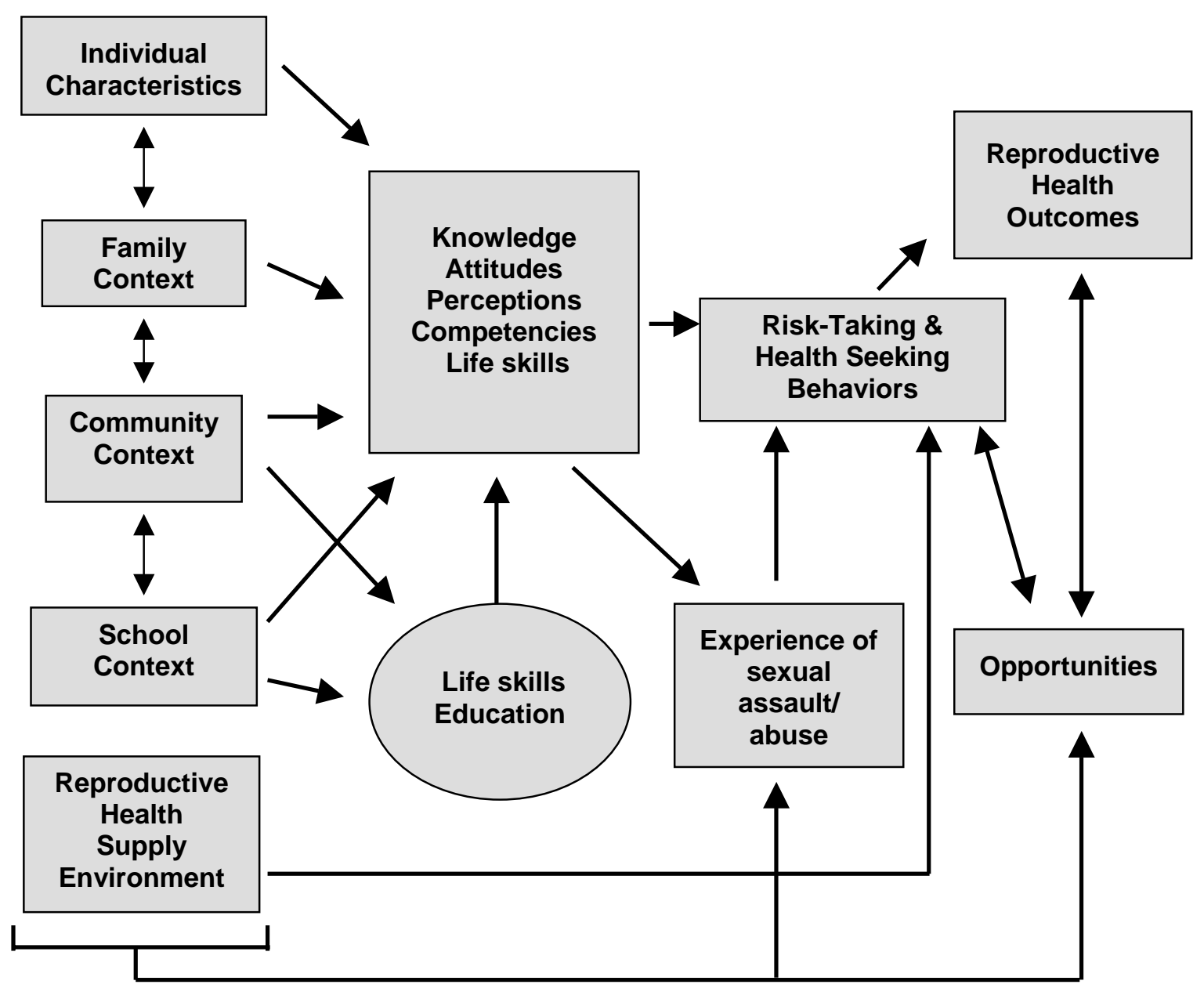

\section{Individual characteristics}

At the individual level, young adults have characteristics that are immutable, such as sex, race, or ethnicity, and age. We posit that the experiences of youth will be conditioned by these characteristics and are important to take into account in hypotheses testing and analysis. Other characteristics such as self-esteem, motivation, and individual capacity will also be important in determining outcomes, but are likely to vary considerably over adolescence and will influence the quality of transitions. For example, their success in school may be a function in part of their own motivation or capacity to learn. 


\section{Hgrizons}

\section{Program variables: Exposure to life skills education}

Life skills education, as mentioned above, is conceptualized here as an independent force in the lives of adolescents. In South Africa at this point in time, life skills education is not rigorously standardized. Although there was a nation-wide training, only those schools that were motivated implemented the program initially, while others elected to modify existing programs. Moreover, life skills education is tailored somewhat idiosyncratically according to the preferences of teachers or the headmaster of the school. Moreover, not all students will attend a life skills course, and those that do attend are likely to be differentially receptive to the materials presented. In short, the extent to which life skills education is effective will depend upon a student's exposure, both in terms of duration and content.

\section{Outcomes}

The outcomes of interest for this analysis are the following:

\section{Knowledge, attitude \& skills}

- Incorrect knowledge score for HIV transmission.

- Knowledge of STIs other than HIV.

- Knowledge of women's STI symptoms.

- Knowledge of men's STI symptoms.

- Knowledge of ways to protect against STIs.

- Knowledge that a girl can get pregnant after having sex only once.

- Number of modern methods of contraceptives recalled.

- Knowledge of a condom source.

- Perceived self-efficacy in acquiring condoms.

- Perceived self-efficacy in using condoms effectively.

\section{Sexual behavior}

- Sexual initiation.

- Secondary abstinence.

- $\quad 2$ partners in the past year.

- $\quad<1$ partner in the past month.

\section{Condom use}

- Condom use during first sex.

- Consistent condom use.

- Condom use during last sex. 


\section{Data and Methods}

\section{Study Setting}

The KwaZulu Natal Province, situated on the east coast of South Africa along the Indian Ocean, is the most populous province in South Africa. At 8.4 million, the population is approximately 45 percent urban, and includes Durban, the largest port and third largest city in the country. About 25 percent of the country's black population resides in the province. Africans, primarily Zuluspeaking, make up about 80 percent of the total population of KZN. The Indian population is the next largest group, at just under 10 percent of the total population, with whites and coloureds comprising the balance. Two administrative areas within KZN-Durban Metro and Mtunzini Magisterial Districts-were purposively selected and their combined populations constitute the universe for the study. These areas were selected to ensure that youth from a wide range of urban, transitional/peri-urban, and rural environments were included in the study. The residence classification used in this report refers to the classification of Census Enumeration Areas (CEAs), the primary sampling unit used for household survey data collection, as either "urban" or "rural" by StatsSA, the South African Census Bureau.

\section{Study Design}

The study has a multi-stage cluster panel survey design, with two rounds of surveys of households and youth undertaken in 1999 and 2001. The individual and household survey data were complemented by surveys of school principals undertaken in 1999 and 2001 (Brown et al. 2003), and a community survey undertaken in mid-2000 (Brown et al. 2001). This analysis focuses on the adolescent youth and household surveys described below.

Sample households (i.e., households with at least one resident 14-22 years of age) were chosen using a modified stratified, multi-stage cluster sampling approach often referred to as the segmentation method (Turner et al. 1996). Prior to fieldwork, CEAs were stratified into race categories (African, Indian, White) based upon their composition. CEAs were allocated to racial categories proportionally to their representation in the population in the two districts. In the first stage of sample selection, 118 CEAs were chosen from a sampling frame consisting of all CEAs in the two districts using a systematic-random sampling procedure with probability-proportional-tosize. At the second stage, CEAs were divided by field supervisors into approximately equal sized segments of about 50 households based upon a quick count of households undertaken as a preliminary field operation. One segment was then selected randomly and field workers attempted to interview all households and youth within that segment, visiting households up to three times. Interviews were conducted by a field worker who was of the same race and sex as the respondent.

Within eligible households, two individual questionnaires were administered. First, a household questionnaire was administered to an adult, preferably the head of household. This interview solicited information on the number and background characteristics of usual residents, household 


\section{Hgrizons}

assets and expenditures (as indicators of socioeconomic position), and knowledge of and attitudes toward selected adolescent sexual and reproductive health issues.

Based on the roster of usual residents obtained in the household interview, all youth between the ages of 14 to 22 years in the 1999 Wave 1 survey, and all youth 14 to 24 years old in the 2001 Wave 2 survey were chosen for an individual interview. These interviews solicited information on a wide range of topics including background characteristics; education and work history; exposure to life skills education in school; exposure to mass media information about sexual and reproductive health issues; knowledge of and attitudes toward selected sexual and reproductive health issues, including the risk of pregnancy and STI/HIV transmission and prevention; sexual and contraceptive behaviors; and pregnancy and childbearing experience.

The fieldwork for the Wave 1 survey was conducted during a six-week period, in September to November 1999. In this first data collection effort, interviews were completed in 1,974 households in 117 of the selected segments, and the head of the household, another adult, or, occasionally an older adolescent responded to the household questionnaire. This yielded a listing of 3770 adolescents between the ages of 14 and 22; of these, individual interviews were completed with 3,052 respondents. Virtually all ( 98.7 percent) of the youth interviewed were matched with household data, resulting in 3,013 adolescents with complete household and individual data.

The fieldwork was conducted by six, two-person teams reflecting the racial composition of KZN province (four African teams, one Indian team, and one White team). Their training included review and practice of the household and individual adolescent questionnaires. Each team was assigned a number of communities (i.e., CEAs). Up to three days were allocated for each CEA. As each team returned from the field, they debriefed with a supervisor. All data were entered and cleaned in South Africa by the local research partners. A report on the descriptive results of Wave 1 data was jointly produced with South African partners (Rutenberg et al. 2001).

Wave 2 data were collected two years later, from September to December 2001. The primary objective of this effort was to collect data from as many of the same individuals interviewed in Wave 1 as possible. Considerable resources were invested in accomplishing this goal, including the allowance of multiple call-backs (at least three); locating youth who had moved, but were still within Durban Metro or Mtunzini Districts; and ultimately sending interviewers out of the study universe, and even out of the province, to try to contact youth who had moved, but for whom contact numbers and/or addresses had been obtained.

The second wave of data collection yielded 2,349 household interviews and 4,185 individual interviews with 14 to 24 year olds. Of these youth, 2,222 had also been interviewed in the Wave 1 survey. The balance includes new 14-15 year olds and other adolescents who were not included in Wave 1 for a variety of reasons (e.g., newly moved into area, not at home during Wave 1). The analysis presented in this report is based on the 2,222 adolescents interviewed in both Waves. Table 1 presents the percent distribution of respondents by background characteristics. More than two-thirds of the sample is between the ages of 14 to 18 at Wave 1 (they are all two years older at Wave 2). There are slightly more females than males largely due to the fact that females were more likely to be in the household to be interviewed. Almost 80 percent of the population is African, 
with the remainder Indian, White, and Coloured. Three-fourths of the study population resides in urban areas by design. Nearly two-thirds (62 percent) of youth were in school during both Waves, 16 percent were not in school during both Waves, and 22 percent were only in school for one of the Waves. At Wave 1 the youth were about evenly divided into the three socioeconomic categories. Socioeconomic status was measured using an index constructed from seven household survey items that asked about housing characteristics and expenditures, including source of drinking water, toilet type, whether the household had electricity, use of paraffin for cooking purposes, monthly expenditure on food and rent, and yearly expenditure on clothes, furniture, and other utilities. A higher score on the index indicated a higher level of household socioeconomic status.

Table 1 Percent distribution of respondents by background characteristics Background characteristic Percent $(n=2,222)$

\section{Age $^{\star}$}

14-18

Sex

Male

46

Female

\section{Population group}

African

Indian

Other (White, Coloured)

Residence

Urban

Rural

Education

Not in school during both waves $\quad 16$

In school during both waves 62

In school at wave 1, but not wave 2 19

In school at wave 2, but not wave 1

Socioeconomic status*

Low

Medium

High

*Age and socioeconomic status during Wave 1

The overall loss-to-follow-up rate was 27 percent. However, the level of success achieved in following youth between the Wave 1 and 2 surveys varied considerably among subgroups, as 


\section{Hgrizons}

displayed in Table 2. Loss to follow-up varied directly with age of youth from a low of 20 percent among 14 to 16 year olds to 34 percent among 20 to 22 year olds; however, there were only modest variations by sex and socioeconomic status. With regard to race, very high rates of panel attrition are observed for the "Other" racial category (55 percent, primarily Whites), while attrition among Indians was relatively low at 20 percent. Additionally, youth from urban areas were considerably more likely to have been lost to follow-up ( 29 percent) than youth from rural areas (19 percent).

Table 2 Percentage of non-response between 1999 and 2001 surveys, by selected characteristics

\begin{tabular}{|c|c|}
\hline Characteristics & Percent \\
\hline \multicolumn{2}{|l|}{ Age } \\
\hline 14-16 & 19.8 \\
\hline $17-19$ & 30.4 \\
\hline $20-22$ & 34.4 \\
\hline \multicolumn{2}{|l|}{ Race } \\
\hline African & 25.8 \\
\hline Indian & 19.9 \\
\hline Other & 55.0 \\
\hline \multicolumn{2}{|l|}{ Sex } \\
\hline Male & 25.8 \\
\hline Female & 28.4 \\
\hline \multicolumn{2}{|l|}{ Residence } \\
\hline Urban & 29.4 \\
\hline Rural & 19.1 \\
\hline \multicolumn{2}{|l|}{ SES $^{a}$} \\
\hline Low & 25.3 \\
\hline Medium & 24.7 \\
\hline High & 31.3 \\
\hline Total & 27.2 \\
\hline \multicolumn{2}{|l|}{${ }^{a} n=3,012$} \\
\hline \multicolumn{2}{|c|}{$\begin{array}{l}\text { As shown in Table } 3 \text {, migration was the primary cause of loss to follow-up among those youth who } \\
\text { were interviewed in Wave } 1 \text {. Twenty-two percent of those lost to follow-up had moved outside the } \\
\text { CEA but remained in the study area, } 12 \text { percent had moved elsewhere in KZN Province, } 22 \text { percent } \\
\text { had moved with no information on their whereabouts, } 11 \text { percent had moved elsewhere in South } \\
\text { Africa, and } 3 \text { percent had left the country. An additional } 17 \text { percent of those lost to follow-up were } \\
\text { not at home and } 5 \text { percent refused to participate during the Wave } 2 \text { survey. Nearly } 5 \text { percent of the } \\
\text { youth lost to follow-up died sometime between the two Waves; cause of death is not known. }\end{array}$} \\
\hline
\end{tabular}




\section{Table 3 Distribution of loss to follow-up by reasons}

\begin{tabular}{|c|c|}
\hline Reasons & $\begin{array}{l}\text { Percent } \\
\mathrm{n}=830\end{array}$ \\
\hline Moved outside CEA but in study area & 22.1 \\
\hline Moved - no information of whereabouts & 21.7 \\
\hline Not at home & 16.9 \\
\hline Moved outside study area but in KZN & 12.1 \\
\hline Moved outside $\mathrm{KZN}$ but in SA & 10.7 \\
\hline Refused to be interviewed & 5.1 \\
\hline Died & 4.8 \\
\hline Moved outside SA & 2.9 \\
\hline Ran away & 1.5 \\
\hline Not eligible & 1.1 \\
\hline In prison/run from police & 1.1 \\
\hline Total & 100 \\
\hline
\end{tabular}

\section{Measurement and Analysis}

\section{Measuring exposure to life skills education}

To measure exposure to life skills education, respondents were asked whether they had been taught about key sexual and reproductive health topics and skills during the four weeks prior to each survey. Coverage of these topics was operationalized as a continuous variable indicating the total number of topics covered, which ranged from 0 to 11 for both waves of data collection; or as a pooled variable for measuring cumulative exposure (explained below), as a count variable with 0 22 counts possible for each respondent.

\section{Measuring changes in outcomes}

Changes in sexual and reproductive health knowledge, attitudes, skills, and behaviors among youth were assessed by comparing relevant indicators measured in the Wave 1 and 2 surveys. Depending upon the type of indicator, $\mathrm{t}, \mathrm{F}$, or Chi-Square tests were used to assess whether the differences observed were statistically significant. Regression models (logit, probit, or ordinary least squares (OLS) regressions, depending upon the outcome variable of interest) were also run to compensate for differences in sample composition between the two surveys. All the regressions included a variable for survey round (Wave $2=1$, Wave $1=0$ ) to control for societal changes. All analyses were stratified by sex, race (African, Indian, Other), and age (14 to 18 years, 19 to 22 years). 


\section{Hgrizons}

\section{Measuring program impact}

Typically, randomized or matched experimental studies with a control group are used to measure the impact of social/public health interventions, such as life skills education. However, as life skills education was theoretically a full coverage program to which all secondary school students were exposed to some degree, this classic design was not possible. Instead, impact was measured by the magnitude of the dose-response relationship between exposure to life skills education and the outcomes of interest, net of changes in other non-programmatic factors (e.g., individual factors such as age, income, etc.). The underlying hypothesis is that, other things being equal, the sexual and reproductive health knowledge, attitudes, skills, and behaviors of youth in the study population will vary systematically depending upon the degree of exposure to life skills education.

The major threat to validity with this design is that youth were not randomly exposed to life skills education. In this case, the key concerns are twofold. First, the program may have targeted high- or low-risk subgroups of youth for early or more intense program implementation. Second, there may have been some self-selection among youth with regard to both exposure or reported exposure and what might predispose them toward or against the protective behaviors advocated by life skills education. If the factors on which the targeting of life skills education is based and/or the ways youth self-select are known and are measured in a given study, these biases can be adequately accounted for by including control variables in multivariate statistical models. However, when exposure is influenced by unobserved (i.e., unmeasured) factors that are also correlated with outcomes under study, the analysis will produce biased estimates of its effect.

It is important when evaluating full coverage programs to use more than one statistical approach if possible in order to address the potential bias and test the robustness of the findings. For this study, two statistical approaches were used:

(1) The first approach, used to estimate impact prospectively over discrete time intervals (e.g., two-, four- or six-years), entails the use of a fixed-effects estimator.

(2) The second approach used a Two Stage Least Squares approach that used instrumental variables to estimate the impact of cumulative exposure to life skills education on knowledge and behavior over the study period.

Details of the statistical approaches are presented in Appendix A. Since the results of the two approaches were similar, in this report we only present the findings from the fixed-effects approach.

Since the models are non-linear, the magnitude of program effects cannot be easily assessed by looking at the regression coefficients. To provide readers with an appreciation of the magnitude of effects observed in the study, a series of policy simulations were run. In the simulations, the observed changes in the knowledge and behavior outcomes were compared to two hypothetical scenarios: one where none of the youth were exposed to life skills education and a second where all of the youth were exposed to all of the topics (this represents the maximum potential impact of life skills education). By comparing the actual levels to the two hypothetical levels (none and all) we can see the magnitude of the impact of exposure to life skills education. 


\section{Results}

\section{Exposure to Life Skills Education}

Exposure to life skills education was measured among youth who reported being in school during the two years prior to each interview. Specifically youth were asked (1) whether their school provided life skills education and (2) which of the 11 life skills topics they recalled being covered in the classroom. Thus exposure in this study is based on student recall.

When reviewing these data, the reader must keep the following in mind. First, all the youth in the study are 2 years older at Wave 2 and therefore, many of the older youth graduate or leave school during this period. Second, not all youth included in the study were at school at one or both survey rounds. Table 4 presents the percent distribution of youth by in-school status during the two waves according to age group, sex, and race. Not surprisingly, the older youth were less likely to be in school. Girls were slightly less likely to be in school than the boys, as were Indians and Other groups. For the impact analysis, those who were not in school at one or both waves were included in the analysis and given a zero for exposure to life skills education.

Table 4 Percent distribution of the respondents by in-school status during the two waves according to age group, sex and race

\begin{tabular}{lccccc}
\hline & $\begin{array}{c}\text { Not in } \\
\text { school } \\
\text { during both } \\
\text { Waves } \\
\mathbf{n}(\%)\end{array}$ & $\begin{array}{c}\text { In school } \\
\text { during both } \\
\text { Waves } \\
\mathbf{n}(\%)\end{array}$ & $\begin{array}{c}\text { In school during } \\
\text { Wave 1 but } \\
\text { not in Wave 2 } \\
\mathbf{n}(\%)\end{array}$ & $\begin{array}{c}\text { In school during } \\
\text { Wave 2 but } \\
\text { not in Wave 1 } \\
\mathbf{n}(\%)\end{array}$ & $\begin{array}{c}\text { Sample } \\
\mathbf{n}(\%)\end{array}$ \\
\hline $\begin{array}{c}\text { Age group* } \\
14-18\end{array}$ & $34(2.6)$ & $1,090(84.8)$ & $128(10.0)$ & $34(2.6)$ & $1,286(100.0)$ \\
$19-22$ & $322(34.4)$ & $284(30.3)$ & $301(32.2)$ & $29(3.1)$ & $936(100.0)$ \\
Sex & & & & & \\
Female & $224(18.7)$ & $687(57.2)$ & $243(20.2)$ & $47(3.9)$ & $1,201(100.0)$ \\
Male & $132(12.9)$ & $687(67.3)$ & $186(18.2)$ & $16(1.6)$ & $1,021(100.0)$ \\
Race & & & & & \\
African & $269(15.7)$ & $1,089(63.6)$ & $291(17.0)$ & $62(3.6)$ & $1,711(100.0)$ \\
Asian & $67(16.8)$ & $226(56.6)$ & $105(26.3)$ & $1(0.3)$ & $399(100.0)$ \\
$\quad$ Other & $20(17.9)$ & $59(52.7)$ & $33(29.5)$ & $0(0.0)$ & $112(100.0)$ \\
Total & $356(16.0)$ & $1,374(61.8)$ & $429(19.3)$ & $63(2.8)$ & $2,222(100.0)$
\end{tabular}

*Age during Wave 1. 


\section{Hgrizons}

Table 5 presents the results of the changes in exposure to the 11 life skills topics over the two-year period in terms of intensity and duration as reported by the students. The first series of rows presents the data for all youth in the study sample and the second presents changes in exposure over time for those youth who reported having ever had sexual intercourse. Among all youth in both the Wave 1 and Wave 2 surveys, the reported overall mean number of topics exposed remains unchanged at 5.1 topics; however we see significant changes by race and age. The mean number of topics that the youth recall being exposed to increases significantly for Africans and younger youth, while it decreases among Indians and older youth. With respect to the distribution of the number of life skills topics, we see an increase in the percentage that report being exposed to no topics (due to the fact that a higher percentage of the youth are not in school at Wave 2), but we also see an increase in the percentage who report being exposed to 10 or 11 topics. This trend is significant for all subgroups. Among those youth who reported having ever had sexual intercourse (who are older than the full sample), we see a significant decrease in the mean number of life skills topics exposed to, with the exception of younger youth among whom the mean number of life skills topics exposed to does not change significantly. The mean number of hours spent on any life skills education did increase significantly for the sexually initiated overall (from 1.9 to 3.5) and among most subgroups, with the exception of Indians and "Others."

Figures 2 and 3 provide further evidence of the increased intensity of exposure to life skills education. The percentage of students who recalled hearing about all 11 life skills topics increased from 15 percent to 36 percent (see Figure 2). Figure 3 shows significant increases in exposure to all 11 topics. 
Table 5 Life skills exposure and intenisty in school (panel), 1999 and 2001

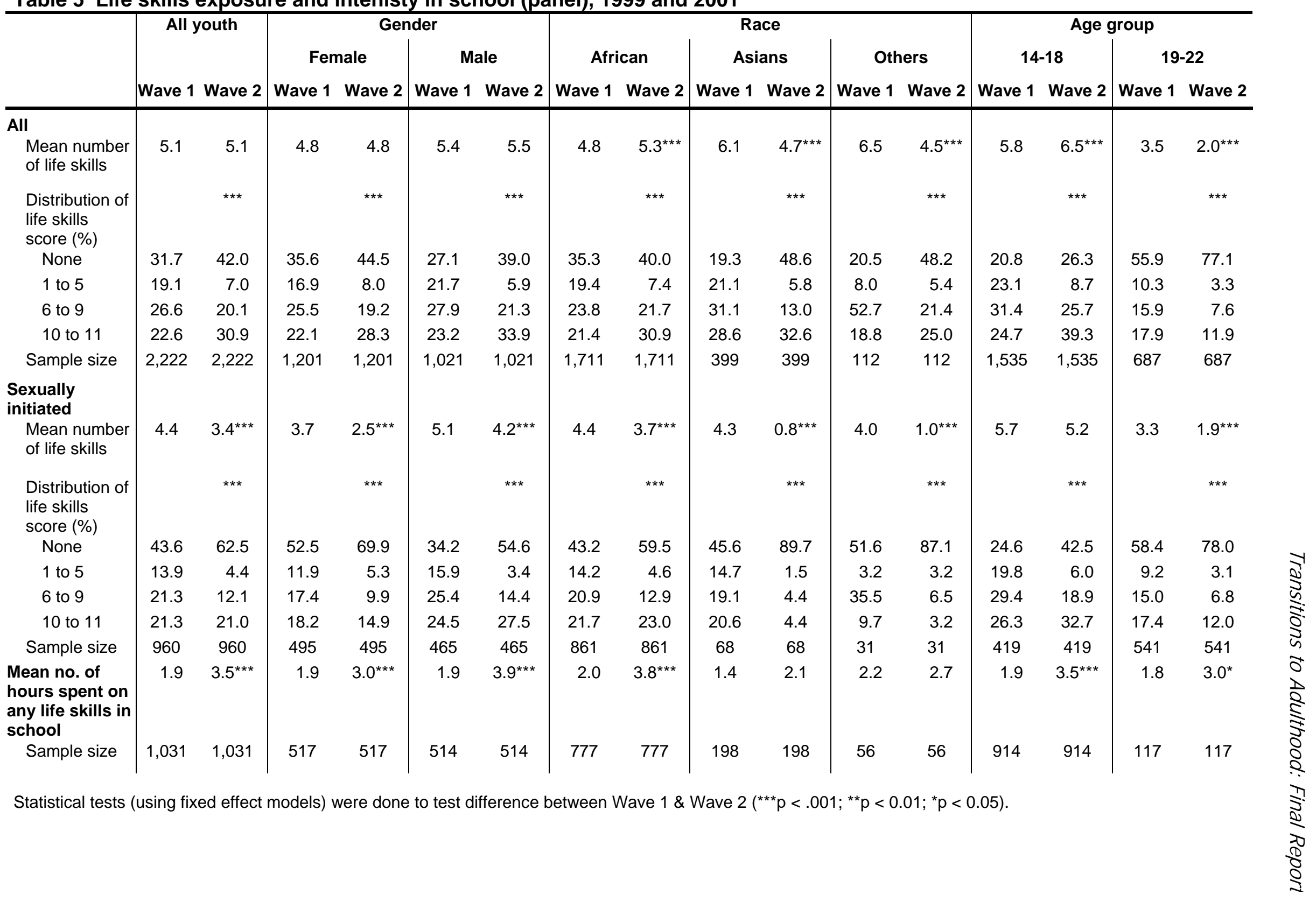




\section{Hgrizons}

Figure 2 Change in life skill subjects recalled being taught in school by students (in school panel)

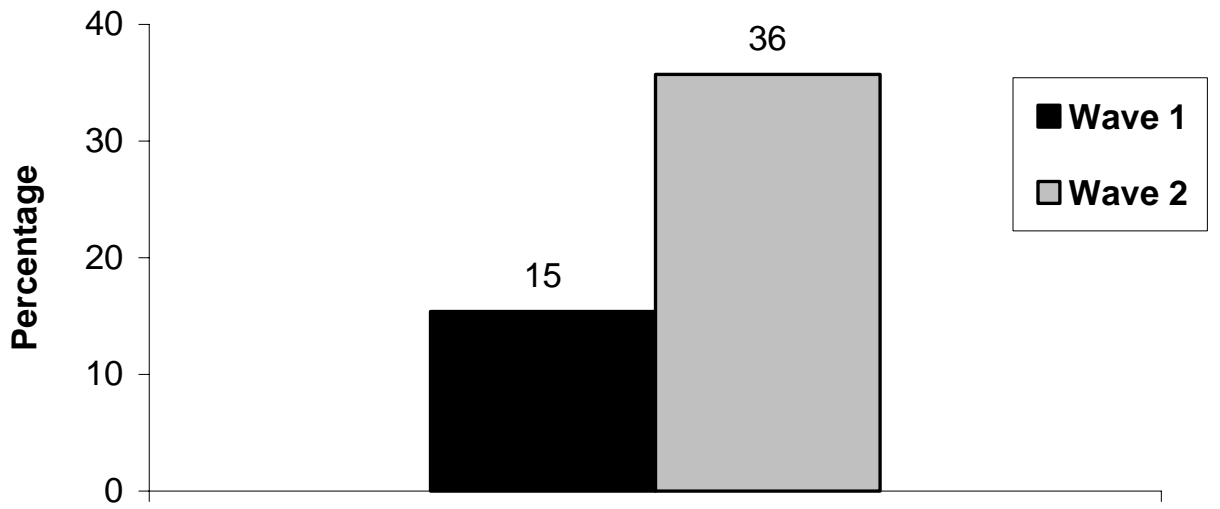

All life skill subjects recalled

Figure 3 Life skill subjects recalled being taught in school by students (in school panel)

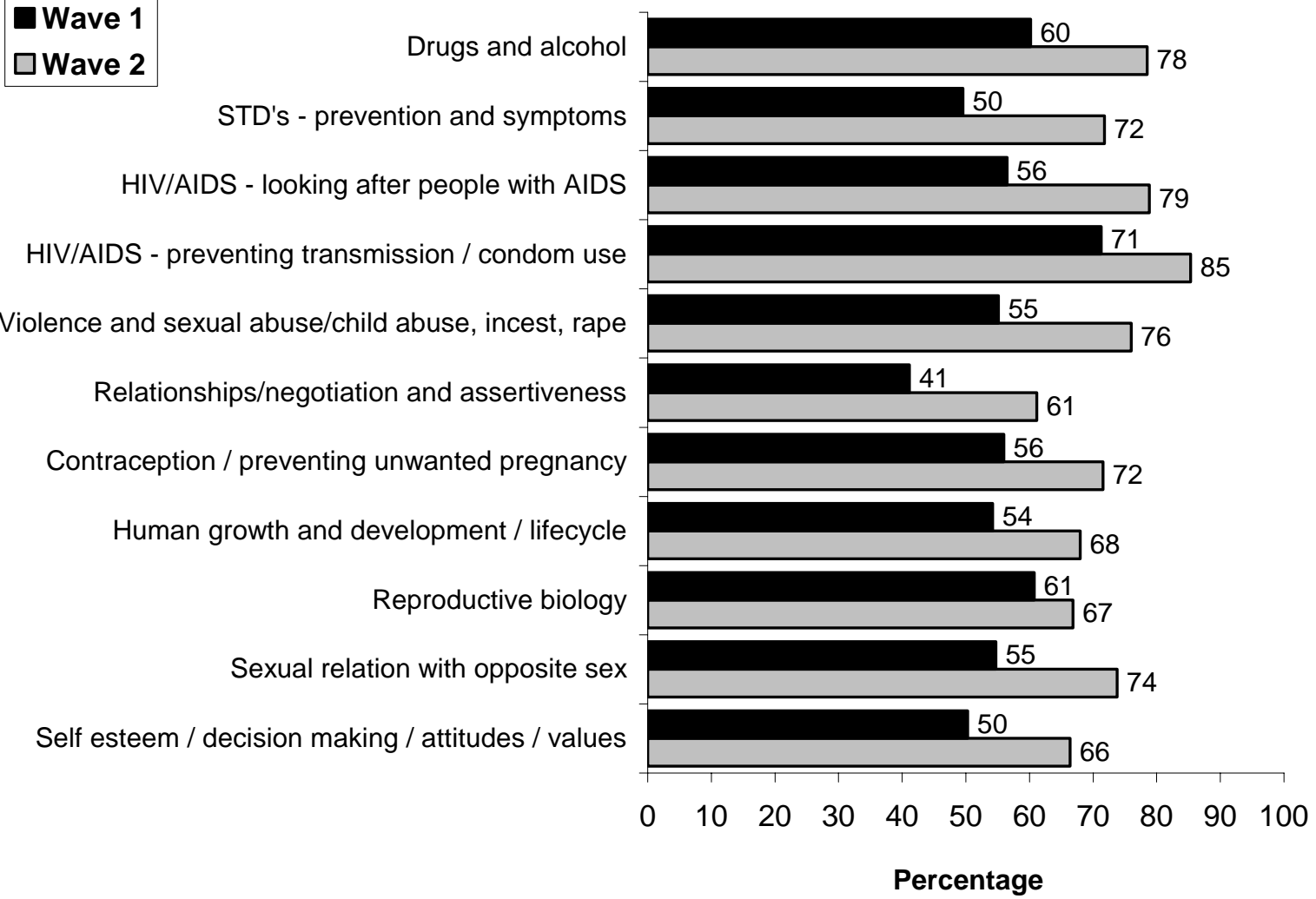


Table 6 illustrates the reports by youth of what they recalled of exposure to life skills education outside of school. Overall we see a significant decrease in the percent of youth who reported any exposure to life skills education outside of school from 40.2 percent to 34.6 percent. However, among those who were exposed, the mean number of hours of exposure increased from 1.6 to 3.9 hours. Soul City, which is a South African NGO that produces a major television series and radio drama to educate about health, was recalled by between 15 and 20 percent of the youth, though we see a significant decrease among females and a significant increase among males. Other important channels appear to be LoveLife and SoulBuddz, particularly among females. LoveLife is another major South African national HIV prevention program aimed at young people, which was launched in September 1999 during Wave 1. While clinical staff (e.g., doctors, nurses) were an important source of information in Wave 1, we observed a significant decrease in the proportion of youth who reported they were a source of life skills education over the two-year period overall and for most subgroups.

In sum, these data show that exposure to life skills education has accelerated in KZN in recent years. It is therefore legitimate to inquire as to what impact this may have had on youth knowledge, attitudes, skills and behaviors, which is presented in the following sections. However, while increases in exposure to sexual and reproductive health information associated with life skills education in schools are apparent, it is also clear that youth in the study population have also been increasingly exposed to relevant information from other non-school sources. This presents a challenge for the impact assessment, as it is necessary to account for the influences of these nonschool efforts in estimating the impact of exposure to life skills education. 
Table 6 Exposure to life skills from other sources during last four weeks of regular school (panel), 1999 and 2001

\begin{tabular}{|c|c|c|c|c|c|c|c|c|c|c|c|c|c|c|c|c|}
\hline & \multirow{2}{*}{\multicolumn{2}{|c|}{ All youth }} & \multicolumn{4}{|c|}{ Gender } & \multicolumn{6}{|c|}{ Race } & \multicolumn{4}{|c|}{ Age group } \\
\hline & & & \multicolumn{2}{|c|}{ Female } & \multicolumn{2}{|c|}{ Male } & \multicolumn{2}{|c|}{ African } & \multicolumn{2}{|c|}{ Asians } & \multicolumn{2}{|c|}{ Others } & \multicolumn{2}{|c|}{$14-18$} & \multicolumn{2}{|c|}{$19-22$} \\
\hline & Wave 1 & Wave 2 & Wave 1 & Wave 2 & Wave 1 & Wave 2 & Wave 1 & Wave 2 & Wave 1 & Wave 2 & Wave 1 & Wave 2 & Wave 1 & Wave 2 & Wave 1 & Wave 2 \\
\hline $\begin{array}{l}\text { Attended any life } \\
\text { skills education } \\
\text { outside school (\%) }\end{array}$ & 40.2 & $34.6^{* *}$ & 37.3 & $26.6^{\star \star \star}$ & 43.2 & 42.6 & 45.8 & $35.2^{\star \star \star}$ & 21.7 & $32.3^{\star *}$ & 27.3 & 34.5 & 39.5 & $34.8^{*}$ & 46.2 & $33.3^{*}$ \\
\hline Sample size & 1,034 & 1,034 & 518 & 518 & 516 & 516 & 781 & 781 & 198 & 198 & 55 & 55 & 917 & 917 & 117 & 117 \\
\hline $\begin{array}{l}\text { Mean no. of hours } \\
\text { spent on life skills } \\
\text { outside school }\end{array}$ & 1.6 & $3.9^{* * *}$ & 1.2 & $3.0^{\star \star \star}$ & 1.8 & $4.4^{* * *}$ & 1.7 & $4.2^{* * *}$ & 1.4 & 2.0 & 1.3 & 2.8 & 1.6 & $4.0^{* * *}$ & 1.5 & $3.2^{*}$ \\
\hline Sample size & 152 & 152 & 57 & 57 & 95 & 95 & 132 & 132 & 18 & 18 & 2 & 2 & 131 & 131 & 21 & 21 \\
\hline $\begin{array}{l}\text { Exposed to life } \\
\text { skills outside } \\
\text { school during past } \\
4 \text { weeks (\%) }\end{array}$ & & & & & & & & & & & & & & & & \\
\hline DRAMAIDE & 2.6 & 2.6 & 2.7 & 1.7 & 2.5 & 3.5 & 3.5 & 3.3 & 0.0 & 0.5 & 0.0 & 0.0 & 2.5 & 2.7 & 3.4 & 1.7 \\
\hline Soul City & 17.9 & 15.9 & 18.5 & $6.9^{\star \star \star}$ & 17.2 & $24.8^{* *}$ & 22.2 & $18.2^{*}$ & 5.6 & 10.6 & 1.8 & 1.8 & 17.7 & 15.7 & 19.7 & 17.1 \\
\hline $\begin{array}{l}\text { Planned } \\
\text { Parenthood }\end{array}$ & 0.5 & 0.2 & 0.4 & 0.2 & 0.6 & 0.2 & 0.6 & 0.1 & 0.0 & 0.5 & 0.0 & 0.0 & 0.5 & 0.2 & 0.0 & 0.0 \\
\hline Lovelife & 0.3 & $5.4^{* * *}$ & 0.0 & 3.1 & 0.6 & $7.8^{\star \star \star}$ & 0.4 & $6.4^{\star * *}$ & 0.0 & 2.0 & 0.0 & 3.6 & 0.3 & $5.5^{\star * *}$ & 0.0 & 5.1 \\
\hline I have hope & 0.2 & 0.0 & 0.2 & 0.0 & 0.2 & 0.0 & 0.3 & 0.0 & 0.0 & 0.0 & 0.0 & 0.0 & 0.2 & 0.0 & 0.0 & 0.0 \\
\hline Soul Buddyz & na & 5.3 & na & 6.4 & na & 4.3 & na & 5.9 & na & 4.0 & na & 1.8 & na & 4.8 & na & 9.4 \\
\hline $\begin{array}{l}\text { Society for } \\
\text { family health }\end{array}$ & 1.1 & 0.6 & 0.2 & 0.6 & 1.9 & 0.6 & 1.4 & $0.4^{\star}$ & 0.0 & 1.5 & 0.0 & 0.0 & 1.0 & 0.7 & 1.7 & 0.0 \\
\hline Aids foundation & 1.4 & 1.0 & 1.5 & 0.8 & 1.2 & 1.2 & 1.5 & 0.8 & 1.0 & 1.0 & 0.0 & 3.6 & 1.2 & 0.9 & 2.6 & 1.7 \\
\hline $\begin{array}{l}\text { Clinic/nurse/ } \\
\text { doctor }\end{array}$ & 7.7 & $2.1^{\star * \star}$ & 4.2 & $1.5^{*}$ & 11.2 & $2.7^{\star \star \star}$ & 10.0 & $1.3^{* \star *}$ & 0.5 & $5.6^{*}$ & 1.8 & 1.8 & 7.6 & $2.4^{\star \star \star}$ & 8.5 & 0.0 \\
\hline $\begin{array}{l}\text { Better life } \\
\text { option }\end{array}$ & 0.2 & 0.1 & 0.2 & 0.0 & 0.2 & 0.2 & 0.3 & 0.1 & 0.0 & 0.0 & 0.0 & 0.0 & 0.2 & 0.0 & 0.0 & 0.9 \\
\hline Church & 1.4 & 0.6 & 1.0 & 0.6 & 1.8 & 0.6 & 1.3 & 0.6 & 1.1 & 0.5 & 3.8 & 0.0 & 1.4 & 0.7 & 1.8 & 0.0 \\
\hline $\begin{array}{l}\text { Other/don't } \\
\text { remember }\end{array}$ & 10.2 & 11.0 & 12.2 & 10.2 & 8.3 & $11.8^{*}$ & 8.2 & 9.7 & 15.3 & 12.6 & 20.4 & 23.6 & 10.0 & 11.5 & 12.2 & 7.7 \\
\hline Sample size* & 1,034 & 1,034 & 518 & 518 & 516 & 516 & 781 & 781 & 198 & 198 & 55 & 55 & 917 & 917 & 117 & 117 \\
\hline
\end{tabular}

Statistical tests using fixed effect models were done to test difference between Wave 1 \& Wave $2\left({ }^{* * *} p<.001 ;{ }^{* *} p<0.01 ;{ }^{*} p<0.05\right)$.

* Adolescent respondents who reported having any Life Skill topics covered in school.

na: This category was not present during Wave 1 survey. 


\section{Changes in Outcome I ndicators}

This section presents the changes in key knowledge, attitude, skill, and behavioral outcome indicators (see Box 1 for list) during the period between the Wave 1 and 2 surveys. The indicators were chosen to reflect the content and intended outcomes of life skills education, and thus changes in a positive/protective direction are anticipated if exposure has an effect. However, as was noted in the presentation of the study methodology, the observation of changes in outcome indicators alone is not sufficient evidence of intervention impact. Estimates of the magnitude of program impact that account for a number of threats to validity are presented in the following section.

\section{Sexual and reproductive health-related knowledge, attitudes and skills}

Knowledge of HIV transmission: Table 7 presents data on the extent of changes in knowledge about transmission of HIV. These data reveal modest gains in knowledge. A small but statistically significant increase in the mean number of correct modes of transmission known is observed for youth in the aggregate, with the largest increases in knowledge observed among males, Africans, and younger adolescents. Specifically, more than 90 percent of youth in all subgroups knew that HIV is sexually transmitted at the time of the Wave 1 survey, and this proportion increased to nearly 97 percent at the time of the Wave 2 survey. However, in the Wave 2 survey only 6 percent and 33 percent of youth, respectively, knew that HIV could be transmitted from mother to child or by sharing needles/unclean instruments. 
Table 7 Knowledge of how one can get infected with HIV/AIDS - panel (in percentages, except where indicated)

\begin{tabular}{|c|c|c|c|c|c|c|c|c|c|c|c|c|c|c|c|c|}
\hline \multirow{3}{*}{$\begin{array}{l}\text { Knowledge } \\
\text { items }\end{array}$} & \multirow{2}{*}{\multicolumn{2}{|c|}{ All youth }} & \multicolumn{4}{|c|}{ Gender } & \multicolumn{6}{|c|}{ Race } & \multicolumn{4}{|c|}{ Age } \\
\hline & & & \multicolumn{2}{|c|}{ Female } & \multicolumn{2}{|c|}{ Male } & \multicolumn{2}{|c|}{ African } & \multicolumn{2}{|c|}{ Indian } & \multicolumn{2}{|c|}{ Other } & \multicolumn{2}{|c|}{$14-18$} & \multicolumn{2}{|c|}{$19-22$} \\
\hline & Wave 1 & Wave 2 & Wave 1 & Wave 2 & Wave 1 & Wave 2 & Wave 1 & Wave 2 & Wave 1 & Wave 2 & Wave 1 & Wave 2 & Wave 1 & Wave 2 & Wave 1 & Wave 2 \\
\hline $\begin{array}{l}\text { Mean number } \\
\text { of correct } \\
\text { response } \\
\text { (range 0-4) }\end{array}$ & 1.8 & $2.0^{\star \star \star \star}$ & 1.9 & $2.0^{\star \star \star}$ & 1.8 & $1.9^{* \star *}$ & 1.7 & $1.9^{* \star *}$ & 2.0 & $2.2^{* \star *}$ & 2.4 & 2.5 & 1.8 & $2.0^{\star \star \star}$ & 1.9 & 2.0 \\
\hline $\begin{array}{l}\text { Sexual } \\
\text { intercourse }\end{array}$ & 94.9 & $97.6^{\star * *}$ & 95.7 & $97.6^{\star *}$ & 93.9 & $97.6^{* * *}$ & 93.9 & $97.8^{\star \star \star}$ & 98.5 & 97.0 & 97.3 & 97.3 & 93.9 & $97.3^{\star \star *}$ & 96.9 & 98.3 \\
\hline $\begin{array}{l}\text { Sharing } \\
\text { needles/ } \\
\text { unclean } \\
\text { instruments }\end{array}$ & 27.0 & $32.9^{\star \star *}$ & 25.6 & $35.6^{\star * *}$ & 28.7 & 29.8 & 19.5 & $25.0^{\star \star \star}$ & 49.9 & $58.4^{* *}$ & 61.6 & 62.5 & 27.5 & $33.9^{\star * *}$ & 26.1 & $30.6^{*}$ \\
\hline $\begin{array}{l}\text { Blood } \\
\text { transfusion/ } \\
\text { contact with } \\
\text { infected blood }\end{array}$ & 57.1 & $60.4^{*}$ & 60.9 & 62.5 & 52.6 & $58.0^{\star *}$ & 57.5 & $61.1^{*}$ & 50.6 & 53.4 & 73.2 & 75.9 & 54.5 & $59.9^{\star \star *}$ & 62.9 & 61.6 \\
\hline $\begin{array}{l}\text { Mother-to-child } \\
\text { transmission }\end{array}$ & 3.3 & $5.8^{* * *}$ & 4.7 & $7.1^{* *}$ & 1.7 & $4.3^{* * *}$ & 2.6 & $4.3^{* * *}$ & 5.5 & $11.0^{* *}$ & 5.4 & 10.7 & 2.9 & $6.3^{* * *}$ & 4.2 & 4.8 \\
\hline Sample size & 2,222 & 2,222 & 1,201 & 1,201 & 1,021 & 1,021 & 1,711 & 1,711 & 399 & 399 & 112 & 112 & 1,535 & 1,535 & 687 & 687 \\
\hline
\end{tabular}

Statistical tests were done (using fixed effect models) to identify significant change between the two waves $\left({ }^{* * *} p<.001 ;{ }^{* *} p<.01 ;{ }^{*} p<.05\right)$.

Age group refers to age of adolescents during Wave 1 
More encouraging is that relatively few youth believed that HIV is transmitted via any of the incorrect modes assessed and this decreased significantly during the study period. Less than 2 percent of youth did not know any mode of transmission (data not shown).

Knowledge of HIV prevention: Table 8 presents data on changes in knowledge of HIV prevention. Only one statistically significant change is observed - an increase in the proportion knowing that abstaining from sex is a protective behavior. The increase is much more significant among females than males, and among older youth. Nearly all youth knew that condom use prevents HIV transmission, but less than 10 percent mentioned limiting number of sex partners or having only one sexual partner. 
Table 8 Knowledge of protective measure against HIV/AIDS infection - panel (in percentages, except where indicated)

\begin{tabular}{|c|c|c|c|c|c|c|c|c|c|c|c|c|c|c|c|c|}
\hline \multirow{3}{*}{$\begin{array}{l}\text { Knowledge } \\
\text { items }\end{array}$} & \multirow{2}{*}{\multicolumn{2}{|c|}{ All youth }} & \multicolumn{4}{|c|}{ Gender } & \multicolumn{6}{|c|}{ Race } & \multicolumn{4}{|c|}{ Age } \\
\hline & & & \multicolumn{2}{|c|}{ Female } & \multicolumn{2}{|c|}{ Male } & \multicolumn{2}{|c|}{ African } & \multicolumn{2}{|c|}{ Indian } & \multicolumn{2}{|c|}{ Other } & \multicolumn{2}{|c|}{$14-18$} & \multicolumn{2}{|c|}{$19-22$} \\
\hline & Wave 1 & Wave 2 & Wave 1 & Wave 2 & Wave 1 & Wave 2 & Wave 1 & Wave 2 & Wave 1 & Wave 2 & Wave 1 & Wave 2 & Wave 1 & Wave 2 & Wave 1 & Wave 2 \\
\hline $\begin{array}{l}\text { Mean number } \\
\text { of correct } \\
\text { responses } \\
\text { (range 0-8) }\end{array}$ & 1.5 & 1.5 & 1.5 & $1.6^{\star \star}$ & 1.5 & 1.5 & 1.4 & $1.5^{\star \star}$ & 1.6 & 1.5 & 1.9 & $1.7^{\star \star}$ & 1.5 & 1.5 & 1.6 & 1.6 \\
\hline $\begin{array}{l}\text { Abstain from } \\
\text { sex }\end{array}$ & 34.6 & $39.5^{\star * *}$ & 36.7 & $42.1^{\star *}$ & 32.1 & $36.4^{*}$ & 36.0 & $42.6^{* \star *}$ & 27.0 & 27.8 & 41.1 & 35.5 & 34.6 & 38.7 & 34.5 & $41.1^{* *}$ \\
\hline $\begin{array}{l}\text { Non- } \\
\text { penetrating } \\
\text { sex }\end{array}$ & 1.6 & 1.0 & 1.5 & 0.9 & 1.8 & 1.1 & 2.0 & $1.1^{*}$ & 0.5 & 0.5 & 0.0 & 0.0 & 1.1 & 0.7 & 2.9 & 1.5 \\
\hline $\begin{array}{l}\text { Always use } \\
\text { condom }\end{array}$ & 93.3 & 94.1 & 91.5 & $93.9^{*}$ & 95.4 & 94.4 & 93.1 & $94.8^{*}$ & 93.8 & 92.5 & 94.4 & 89.7 & 92.1 & 93.8 & 95.7 & 94.8 \\
\hline $\begin{array}{l}\text { Limit } \\
\text { number of } \\
\text { sex partners }\end{array}$ & 2.3 & 2.2 & 2.4 & 2.4 & 2.2 & 2.0 & 1.7 & 1.9 & 3.6 & 3.6 & 6.5 & 1.9 & 1.9 & 2.0 & 3.2 & 2.7 \\
\hline $\begin{array}{l}\text { Have only } \\
\text { one sexual } \\
\text { partner }\end{array}$ & 7.4 & 6.4 & 8.7 & 8.2 & 5.9 & 4.3 & 5.7 & 5.3 & 13.6 & 11.3 & 9.3 & 3.7 & 6.7 & 6.0 & 9.0 & 7.2 \\
\hline $\begin{array}{l}\text { Avoid sex } \\
\text { worker }\end{array}$ & 0.6 & 0.6 & 0.5 & 0.5 & 0.6 & 0.7 & 0.3 & 0.6 & 1.8 & 0.8 & 0.9 & 0.0 & 0.6 & 0.6 & 0.6 & 0.8 \\
\hline $\begin{array}{l}\text { Use } \\
\text { sterilized } \\
\text { needle }\end{array}$ & 7.4 & 7.4 & 7.0 & 9.1 & 7.8 & $5.4^{*}$ & 3.5 & 4.1 & 16.5 & 14.7 & 30.8 & 29.0 & 7.3 & 7.9 & 7.5 & 6.1 \\
\hline $\begin{array}{l}\text { Ask partner } \\
\text { to take HIV } \\
\text { test }\end{array}$ & 2.3 & 1.4 & 2.8 & $1.3^{*}$ & 1.8 & 1.6 & 1.3 & 0.8 & 5.4 & $2.3^{*}$ & 5.6 & 6.5 & 2.4 & 1.5 & 2.1 & 1.2 \\
\hline Sample size & 2,067 & 2,067 & 1,116 & 1,116 & 951 & 951 & 1,571 & 1,571 & 389 & 389 & 107 & 107 & 1,412 & 1,412 & 655 & 655 \\
\hline
\end{tabular}

Statistical tests were done (using fixed effect models) to identify significant change between the two waves $\left({ }^{* * *} p<.001 ;{ }^{* *} p<.01 ;{ }^{*} p<.05\right.$ )

Age group refers to age of adolescents during Wave 1. 
Knowledge of STIs: Survey respondents were asked if they had heard of STIs and to name STI symptoms in men and women. Table 9 summarizes findings with regard to changes over time and indicates substantial gains in awareness of STIs during the study period. The proportion of youth who had heard of STIs increased by 18 percentage points, reaching 61 percent in the Wave 2 survey. Gains of comparable magnitude are observed among all subgroups of youth except the "Other" racial category, where awareness of STIs was already high at Wave 1.

The data indicate more modest gains with regard to knowledge about STI symptoms, although increases in the mean reported number of symptoms for both males and females were statistically significant. The largest increase was observed in knowledge of discharge as a symptom for both males and females. These gains appear to have been somewhat larger among African than Indian youth and among younger vs. older youth. 
Table 9 Knowledge of STI symptoms - panel (in percentages, except where indicated)

\begin{tabular}{|c|c|c|c|c|c|c|c|c|c|c|c|c|c|c|c|c|}
\hline & \multirow{2}{*}{\multicolumn{2}{|c|}{ All youth }} & \multicolumn{4}{|c|}{ Gender } & \multicolumn{6}{|c|}{ Race } & \multicolumn{4}{|c|}{ Age group } \\
\hline & & & Fen & iale & & le & Afri & $\operatorname{can}$ & & & Oth & ers & & 18 & 19 & \\
\hline & Wave 1 & Wave 2 & Wave 1 & Wave 2 & Wave 1 & Wave 2 & Wave 1 & Wave 2 & Wave 1 & Wave 2 & Wave 1 & Wave 2 & Wave 1 & Wave 2 & Wave 1 & Wave 2 \\
\hline $\begin{array}{l}\text { Percentage heard of } \\
\text { STIs other than } \\
\text { HIV/AIDS }\end{array}$ & 42.2 & $60.7^{* * *}$ & 42.4 & $61.4^{* \star *}$ & 41.9 & $59.8^{* * *}$ & 41.8 & $61.3^{* \star \star}$ & 34.1 & 52.9 & 75.9 & 80.4 & 35.2 & $56.2^{\star \star \star}$ & 57.8 & $70.7^{\star \star \star}$ \\
\hline Sample size & 2,222 & 2,222 & 1,201 & 1,201 & 1,021 & 1,021 & 1,711 & 1,711 & 399 & 399 & 112 & 112 & 1,535 & 1,535 & 687 & 687 \\
\hline $\begin{array}{l}\text { Mean no. of women's } \\
\text { STI symptoms } \\
\text { recalled (range 0-6) }\end{array}$ & 1.0 & $1.2^{\star \star \star}$ & 1.3 & $1.5^{\star \star \star}$ & 0.7 & $0.9^{\star \star \star}$ & 1.1 & $1.4^{\star \star \star}$ & 0.7 & $0.9^{*}$ & 0.8 & 0.9 & 0.9 & $1.2^{\star \star \star}$ & 1.2 & 1.3 \\
\hline Abdominal pain & 8.5 & 10.5 & 10.3 & 6.7 & 6.2 & $15.4^{\star * \star}$ & 10.3 & 12.6 & 1.9 & 5.7 & 3.9 & 1.3 & 5.5 & $10.0^{*}$ & 12.3 & 11.0 \\
\hline $\begin{array}{l}\text { Foul smelling } \\
\text { discharge }\end{array}$ & 27.8 & $42.1^{* \star *}$ & 35.6 & $50.4^{\star \star *}$ & 17.8 & $31.4^{* * *}$ & 33.1 & $48.8^{\star \star \star}$ & 9.4 & $20.8^{\star}$ & 14.5 & 22.4 & 20.6 & $38.5^{\star \star \star}$ & 37.1 & $46.6^{* *}$ \\
\hline $\begin{array}{l}\text { Burning pain on } \\
\text { urination }\end{array}$ & 13.0 & 15.3 & 13.1 & $20.0^{\star *}$ & 12.9 & 9.2 & 14.9 & 17.3 & 4.7 & 9.4 & 10.5 & 9.2 & 10.0 & 13.2 & 16.9 & 18.1 \\
\hline Genital ulcers/sores & 37.0 & 36.8 & 52.0 & 49.9 & 17.5 & 20.0 & 37.4 & 36.8 & 35.8 & 36.8 & 35.5 & 36.8 & 37.6 & 37.8 & 36.2 & 35.6 \\
\hline Swelling in groin & 7.5 & 8.5 & 6.9 & 8.4 & 8.3 & 8.6 & 7.5 & 9.1 & 9.4 & 5.7 & 5.3 & 7.9 & 7.7 & 8.1 & 7.4 & 8.9 \\
\hline Itching & 9.0 & 11.6 & 11.5 & 16.0 & 5.8 & 5.8 & 9.3 & 10.7 & 6.6 & $16^{*}$ & 10.5 & 11.8 & 7.4 & 10.8 & 11.0 & 12.6 \\
\hline $\begin{array}{l}\text { Mean no. of men's } \\
\text { STI symptoms } \\
\text { recalled (range 0-6) }\end{array}$ & 1.1 & $1.4^{* * *}$ & 1.1 & $1.2^{*}$ & 1.2 & $1.5^{\star \star *}$ & 1.3 & $1.5^{\star * *}$ & 0.7 & $1.0^{*}$ & 0.8 & 0.9 & 1.0 & $1.3^{*}$ & 1.3 & 1.5 \\
\hline Genital discharge & 27.3 & $33.9^{* *}$ & 26.5 & 27.2 & 28.3 & $42.5^{\star \star \star}$ & 32.7 & $40.6^{* *}$ & 8.5 & 11.3 & 13.2 & 15.8 & 22.2 & $29.7^{*}$ & 33.7 & 39.3 \\
\hline $\begin{array}{l}\text { Burning pain on } \\
\text { urination }\end{array}$ & 21.1 & $30.4^{* \star *}$ & 14.6 & $23.2^{* *}$ & 29.5 & $39.7^{* *}$ & 25.8 & $35.8^{* * *}$ & 4.7 & $15.1^{*}$ & 9.2 & 11.8 & 15.6 & $28.0^{* * *}$ & 28.2 & 33.4 \\
\hline Itching & 12.1 & 12.9 & 10.7 & 11.2 & 13.8 & 15.1 & 13.0 & $12.6^{\star *}$ & 4.7 & 17.0 & 15.8 & 9.2 & 10.5 & 11.7 & 14.1 & 14.4 \\
\hline Genital ulcers/sores & 40.9 & 39.9 & 46.3 & 45.8 & 33.8 & 32.3 & 43.4 & 39.9 & 34.0 & 39.6 & 31.6 & 40.8 & 40.4 & 40.9 & 41.4 & 38.7 \\
\hline Swelling in groin & 10.3 & $13.7^{\star}$ & 9.1 & 12.6 & 12.0 & 15.1 & 9.4 & $14.8^{\star *}$ & 14.2 & 8.5 & 11.8 & 13.2 & 8.4 & 12.2 & 12.9 & 15.6 \\
\hline $\begin{array}{l}\text { Can't retract } \\
\text { foreskin }\end{array}$ & 2.2 & $4.4^{*}$ & 2.4 & 3.1 & 1.8 & $6.2^{* *}$ & 2.7 & 4.8 & 0.0 & 3.8 & 1.3 & 2.6 & 1.2 & $4.5^{\star \star}$ & 3.4 & 4.3 \\
\hline Sample size & 744 & 744 & 419 & 419 & 325 & 325 & 562 & 562 & 106 & 106 & 76 & 76 & 418 & 418 & 326 & 326 \\
\hline
\end{tabular}

Statistical tests were done (using fixed effect models) to identify significant change between the two waves $\left({ }^{\star * *} p<.001 ;{ }^{* *} p<.01 ;{ }^{*} p<.05\right.$ ) Age group refers to age of adolescents during Wave 1. 
Knowledge of STI prevention: Table 10 presents data on changes in knowledge of protective measures against transmission of STIs. There is some evidence of improved knowledge of effective methods to prevent STI transmission for the panel of youth. Most knew that condom use protects against STI transmission in the Wave 1 survey; little change was observed in Wave 2. Among the other correct methods, sizeable and significant changes are noted only in knowledge of abstinence as a method to prevent STI transmission. 
Table 10 Knowledge of ways to prevent STIs - panel (in percentages, except where indicated)

\begin{tabular}{|c|c|c|c|c|c|c|c|c|c|c|c|c|c|c|c|c|}
\hline & \multirow{2}{*}{\multicolumn{2}{|c|}{ All youth }} & \multicolumn{4}{|c|}{ Gender } & \multicolumn{6}{|c|}{ Race } & \multicolumn{4}{|c|}{ Age group } \\
\hline & & & \multicolumn{2}{|c|}{ Female } & \multicolumn{2}{|c|}{ Male } & \multicolumn{2}{|c|}{ African } & \multicolumn{2}{|c|}{ Indian } & \multicolumn{2}{|c|}{ Others } & \multicolumn{2}{|c|}{$14-18$} & \multicolumn{2}{|c|}{$19-22$} \\
\hline & Wave 1 & Wave 2 & Wave 1 & Wave 2 & Wave 1 & Wave 2 & Wave 1 & Wave 2 & Wave 1 & Wave 2 & Wave 1 & Wave 2 & Wave 1 & Wave 2 & Wave 1 & Wave 2 \\
\hline $\begin{array}{l}\text { Mean correct } \\
\text { response } \\
\text { (range 0-4) }\end{array}$ & 1.1 & $1.2^{* \star}$ & 1.1 & $1.2^{*}$ & 1.0 & $1.2^{\star \star}$ & 1.0 & $1.1^{* *}$ & 1.3 & 1.2 & 1.4 & 1.4 & 1.1 & $1.2^{* \star *}$ & 1.1 & 1.1 \\
\hline Use condom & 82.0 & 84.7 & 80.0 & 81.4 & 84.3 & 88.7 & 86.0 & 88.3 & 75.7 & 74.4 & 57.6 & 67.8 & 76.5 & $83.5^{\star \star \star}$ & 89.4 & 86.8 \\
\hline $\begin{array}{l}\text { Avoid casual } \\
\text { partners }\end{array}$ & 9.2 & 6.4 & 11.4 & 6.8 & 6.5 & 5.9 & 4.7 & 3.6 & 22.1 & 14.7 & 25.9 & 18.9 & 10.4 & 7.1 & 7.6 & 5.1 \\
\hline Abstinence & 17.7 & $24.7^{* * *}$ & 21.8 & $29.0^{* \star *}$ & 12.9 & $19.5^{\star *}$ & 12.3 & $20.7^{* \star \star}$ & 25.0 & 31.3 & 51.8 & 55.6 & 20.0 & $26.8^{* * *}$ & 14.6 & $21.0^{*}$ \\
\hline $\begin{array}{l}\text { Avoid sex } \\
\text { workers }\end{array}$ & 1.0 & 0.8 & 0.8 & 0.5 & 1.2 & 1.1 & 0.7 & 0.8 & 2.2 & 0.9 & 1.2 & 1.1 & 1.1 & 0.7 & 0.8 & 1.0 \\
\hline Sample size & 937 & 1349 & 509 & 738 & 428 & 611 & 716 & 1048 & 136 & 211 & 85 & 90 & 540 & 863 & 397 & 486 \\
\hline
\end{tabular}

Statistical tests were done (using fixed effect models) to identify significant change between the two waves $\left({ }^{* * *} p<.001 ;{ }^{* *} p<.01 ;{ }^{*} p<.05\right)$. Age group refers to age of adolescents during Wave 1. 
Knowledge of pregnancy risk: Table 11 presents evidence on changes in knowledge of behaviors that put females at risk of pregnancy. Two knowledge items are considered: (1) the period of the female menstrual cycle during which there is the greatest risk of pregnancy and (2) whether women can become pregnant the first time they have sex. With regard to knowledge of the female menstrual cycle, only a small proportion of youth answered this question correctly, and no substantial changes in knowledge are observed over time. Youth were relatively knowledgeable as to whether women can become pregnant the first time they have sex at the time of the Wave 1 survey, yet there were still significant increases in knowledge levels among all youth, with the exception of the "Other" racial category, where knowledge was very high (96 percent) at the time of the Wave 1 survey. 
Table 11 Correct knowledge of pregnancy risk - panel (in percentages)

\begin{tabular}{|c|c|c|c|c|c|c|c|c|c|c|c|c|c|c|c|c|}
\hline & \multirow{2}{*}{\multicolumn{2}{|c|}{ All youth }} & \multicolumn{4}{|c|}{ Gender } & \multicolumn{6}{|c|}{ Race } & \multicolumn{4}{|c|}{ Age group } \\
\hline & & & Fen & ale & $\mathbf{M}$ & & Afri & can & Ind & & Oth & & 14 & & & 22 \\
\hline & Wave 1 & Wave 2 & Wave 1 & Wave 2 & Wave 1 & Wave 2 & Wave 1 & Wave 2 & Wave 1 & Wave 2 & Wave 1 & Wave 2 & Wave 1 & Wave 2 & Wave 1 & Wave 2 \\
\hline $\begin{array}{l}\text { Part of monthly } \\
\text { cycle a girl is at the } \\
\text { highest risk }\end{array}$ & 6.4 & 5.7 & 6.9 & 7.2 & 5.7 & 4.0 & 4.9 & 4.3 & 8.5 & 9.3 & 20.5 & 14.3 & 5.2 & 5.8 & 8.9 & $5.5^{*}$ \\
\hline $\begin{array}{l}\text { A girl can get } \\
\text { pregnant if she had } \\
\text { sex only once }\end{array}$ & 78.6 & $88.4^{* * *}$ & 82.4 & $88.8^{* * *}$ & 74.1 & $88.0^{\star * *}$ & 75.1 & $86.5^{\star * *}$ & 88.5 & $96.0^{* * *}$ & 96.4 & 92.0 & 73.2 & $85.9^{\star \star *}$ & 90.5 & $94.2^{* *}$ \\
\hline Sample size & 2,217 & 2,217 & 1,200 & 1,200 & 1,017 & 1,017 & 1,706 & 1,706 & 399 & 399 & 112 & 112 & 1,530 & 1,530 & 687 & 687 \\
\hline
\end{tabular}

Statistical tests were done (using fixed effect models) to identify significant change between the two waves $\left({ }^{* * *} p<.001 ;{ }^{* *} p<.01 ;{ }^{*} p<.05\right)$.

Age group refers to age of adolescents during Wave 1. 
Knowledge of contraceptive methods: Table 12 presents data on changes in knowledge of contraception. Statistically significant increases in the mean number of modern methods and total number of methods known are observed for most population subgroups. With regard to individual methods, statistically significant increases in knowledge were observed for oral contraceptives, condoms, and injectables.

The sizeable differentials in knowledge by sex and race indicated by the Wave 2 data are noteworthy. Females are significantly more knowledgeable about pills and injectables than males, while males are more knowledgeable about condoms. Interestingly, African youth are equally knowledgeable about condoms, oral contraceptives, and injectables, but lag behind youth in the "Other" category in their awareness of oral contraceptives and condoms. On the other hand, they exceed Indian and "Other" youth in their knowledge of injectables. 
Table 12 Knowledge of contraceptive methods - panel (in percentages, except where indicated) All youth Gender

Race

Age group

\begin{tabular}{l|l|l|l|l|l|l|l|l|} 
Female & Male & African & Indian & Others & $14-18$ & $19-22$
\end{tabular}

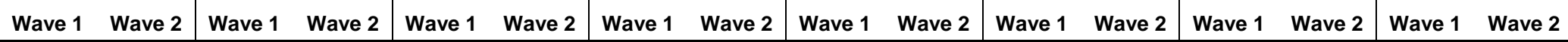

\begin{tabular}{|c|c|c|c|c|c|c|c|c|c|c|c|c|c|c|c|c|}
\hline $\begin{array}{l}\text { Mean number of } \\
\text { modern methods } \\
\text { (range } 0-4 \text { ) }\end{array}$ & 1.9 & $2.1^{\star * \star}$ & 2.1 & $2.3^{* \star *}$ & 1.6 & $1.9^{\star \star \star}$ & 1.9 & $2.1^{* \star *}$ & 1.6 & $1.9^{\star \star \star}$ & 2.0 & 2.2 & 1.7 & $2.0^{\star \star \star}$ & 2.2 & $2.3^{*}$ \\
\hline Pill & 64.9 & $71.4^{* \star *}$ & 80.6 & 82.8 & 46.5 & $57.9^{\star \star \star}$ & 63.2 & $70.1^{* * *}$ & 69.2 & $75.4^{*}$ & 75.9 & 76.8 & 59.6 & $67.9^{\star \star \star}$ & 76.9 & 79.2 \\
\hline Injectables & 51.2 & $60.7^{\star \star *}$ & 70.4 & $78.9^{\star \star \star}$ & 28.6 & $39.4^{\star \star \star}$ & 62.0 & $71.2^{\star \star *}$ & 12.5 & $25.8^{* * *}$ & 23.2 & 25.0 & 43.5 & $55.2^{\star \star *}$ & 68.4 & $73.1^{*}$ \\
\hline Condoms & 66.1 & $72.3^{\star \star *}$ & 53.3 & $61.9^{\star \star \star}$ & 81.2 & $84.6^{*}$ & 62.0 & $68.7^{\star \star \star}$ & 76.4 & 81.2 & 92.0 & 95.5 & 63.1 & $72.4^{* \star *}$ & 72.8 & 72.1 \\
\hline $\begin{array}{l}\text { Female } \\
\text { condoms }\end{array}$ & 3.2 & $5.7^{\star \star *}$ & 2.3 & 3.2 & 4.2 & $8.5^{\star \star \star *}$ & 2.2 & $4.4^{\star \star \star}$ & 4.8 & 6.3 & 12.5 & 22.3 & 3.1 & $5.3^{\star *}$ & 3.5 & $6.6^{*}$ \\
\hline $\begin{array}{l}\text { Mean number of } \\
\text { traditional } \\
\text { methods } \\
\text { (range } 0-5 \text { ) }\end{array}$ & 0.1 & 0.1 & 0.1 & 0.1 & 0.1 & 0.1 & 0.1 & 0.1 & 0.0 & $0.1^{*}$ & 0.1 & 0.1 & 0.1 & 0.1 & 0.1 & 0.1 \\
\hline $\begin{array}{l}\text { Traditional/ } \\
\text { Herbs }\end{array}$ & 0.1 & 0.2 & 0.2 & 0.2 & 0.0 & 0.3 & 0.2 & 0.3 & 0.0 & 0.0 & 0.0 & 0.0 & 0.0 & 0.3 & 0.4 & 0.0 \\
\hline Washing & 0.0 & 0.0 & 0.1 & 0.0 & 0.0 & 0.0 & 0.1 & 0.0 & 0.0 & 0.0 & 0.0 & 0.0 & 0.0 & 0.0 & 0.1 & 0.0 \\
\hline $\begin{array}{l}\text { Non- } \\
\text { penetrating } \\
\text { sex }\end{array}$ & 1.5 & 1.6 & 1.7 & 2.2 & 1.3 & 1.0 & 1.9 & 1.9 & 0.0 & 0.8 & 0.9 & 0.0 & 0.8 & 1.4 & 3.1 & 2.0 \\
\hline Safe days & 4.6 & 5.4 & 4.8 & $7.2^{*}$ & 4.3 & 3.1 & 4.5 & 4.7 & 3.3 & $6.3^{*}$ & 10.7 & 11.6 & 5.0 & 5.5 & 3.8 & 5.1 \\
\hline Withdrawal & 1.9 & $0.9^{* *}$ & 1.9 & $0.7^{*}$ & 1.9 & 1.0 & 2.0 & $0.6^{\star *}$ & 1.0 & 1.5 & 2.7 & 1.8 & 1.3 & $0.6^{*}$ & 3.2 & $1.5^{*}$ \\
\hline $\begin{array}{l}\text { Mean number of } \\
\text { methods } \\
\text { (range 0-9) }\end{array}$ & 1.9 & $2.2^{\star * *}$ & 2.2 & $2.4^{\star \star * *}$ & 1.7 & $2.0^{\star \star * *}$ & 2.0 & $2.2^{\star \star \star *}$ & 1.7 & $2.0^{* * *}$ & 2.2 & 2.3 & 1.8 & $2.1^{* \star *}$ & 2.3 & 2.4 \\
\hline Sample size & 2,222 & 2,222 & 1,201 & 1,201 & 1,021 & 1,021 & 1,711 & 1,711 & 399 & 399 & 112 & 112 & 1,535 & 1,535 & 687 & 687 \\
\hline
\end{tabular}

Statistical tests were done (using fixed effect models) to identify significant change between the two waves $\left({ }^{* * *} p<.001 ;{ }^{* *} p<.01 ;{ }^{*} p<.05\right)$.

Age group refers to age of adolescents during Wave 1. 
Knowledge of where to get condoms: As observed in Table 13, youth in KZN are well informed about where to obtain condoms. Over 90 percent of youth in all subgroups knew where to obtain condoms at the time of the Wave 1 survey, and overall, this proportion increased slightly among the subgroups between the two surveys. Virtually all youth in the panel knew where to obtain condoms at the time of the Wave 2 survey. Thus, lack of knowledge of condoms and where to obtain them is clearly not an obstacle to consistent use in the study population. 
Table 13 Knowledge of condom source - panel (in percentages, except where indicated)

\begin{tabular}{|c|c|c|c|c|c|c|c|c|c|c|c|c|c|c|c|c|}
\hline & \multirow{2}{*}{\multicolumn{2}{|c|}{ All youth }} & \multicolumn{4}{|c|}{ Gender } & \multicolumn{6}{|c|}{ Race } & \multicolumn{4}{|c|}{ Age group } \\
\hline & & & Fen & Iale & & & Afri & can & & lian & Otr & ers & & 18 & & 22 \\
\hline & Wave 1 & Wave 2 & Wave 1 & Wave 2 & Wave 1 & Wave 2 & Wave 1 & Wave 2 & Wave 1 & Wave 2 & Wave 1 & Wave 2 & Wave 1 & Wave 2 & Wave 1 & Wave 2 \\
\hline $\begin{array}{l}\text { Knows where to get } \\
\text { condoms }\end{array}$ & 95.5 & $98.5^{\star * *}$ & 94.9 & $97.8^{* * *}$ & 96.3 & $99.3^{* * *}$ & 95.4 & $98.2^{\star \star \star}$ & 95.7 & $99.0^{*}$ & 97.3 & 100.0 & 94.2 & $98.0^{* \star \star}$ & 98.5 & 99.4 \\
\hline Sample size & 2,222 & 2,222 & 1,201 & 1,201 & 1,021 & 1,021 & 1,711 & 1,711 & 399 & 399 & 112 & 112 & 1,535 & 1,535 & 687 & 687 \\
\hline $\begin{array}{l}\text { Mean of confident in } \\
\text { getting condom } \\
\text { when needed index }\end{array}$ & 2.5 & $2.8^{\star \star *}$ & 2.3 & $2.7^{\star \star \star}$ & 2.7 & $2.8^{\star *}$ & 2.5 & $2.7^{\star \star \star}$ & 2.5 & $2.8^{\star \star \star}$ & 2.7 & $2.9^{\star \star \star}$ & 2.4 & $2.7^{\star \star \star}$ & 2.7 & $2.8^{\star \star \star}$ \\
\hline $\begin{array}{l}\text { \% reported very } \\
\text { confident in getting } \\
\text { condom when } \\
\text { needed }\end{array}$ & 70.3 & $83.4^{\star \star *}$ & 59.5 & $81.5^{\star \star *}$ & 82.7 & 85.6 & 69.6 & $81.8^{\star \star \star}$ & 70.5 & $87.1^{* \star *}$ & 79.8 & $93.6^{* *}$ & 66.0 & $82.0^{* \star \star}$ & 79.6 & $86.4^{* *}$ \\
\hline $\begin{array}{l}\text { Mean of confident in } \\
\text { using condom } \\
\text { effectively index }\end{array}$ & 2.0 & $2.4^{* \star *}$ & 1.7 & $2.2^{\star \star \star *}$ & 2.3 & $2.7^{\star \star \star}$ & 2.0 & $2.4^{* \star \star}$ & 2.2 & $2.5^{\star \star \star}$ & 2.4 & $2.6^{\star \star \star}$ & 1.9 & $2.3^{\star \star *}$ & 2.2 & $2.6^{\star \star \star}$ \\
\hline $\begin{array}{l}\% \text { reported very } \\
\text { confident in using } \\
\text { condom effectively }\end{array}$ & 43.4 & $62.4^{* * *}$ & 29.1 & $49.7^{* * *}$ & 59.6 & $76.5^{\star \star \star}$ & 41.5 & $61.4^{\star \star *}$ & 46.3 & $62.7^{\star \star \star}$ & 59.6 & $76.1^{* *}$ & 38.3 & $58.0^{\star \star \star *}$ & 54.2 & $71.8^{* * *}$ \\
\hline Sample size & 2,090 & 2,090 & 1,114 & 1,114 & 976 & 976 & 1,601 & 1,601 & 380 & 380 & 109 & 109 & 1,423 & 1,423 & 667 & 667 \\
\hline
\end{tabular}

Both the scale ranges from 1 to 3 ; higher score indicates more confident.

Statistical tests were done using fixed effect models to identify significant change between the two waves $\left({ }^{* \star *} p<.001 ;{ }^{* *} p<.01 ;{ }^{*} p<.05\right)$

Age group refers to age of adolescents during Wave 1. 
Perceived condom self-efficacy: Table 14 also presents data on changes in perceived condom selfefficacy. Two aspects of self-efficacy are considered-confidence in their ability to obtain condoms when needed and confidence in their ability to use them effectively. Changes in two indicators are presented for each: (1) a three-item efficacy index and (2) the proportion of youth who reported being very confident in their ability to obtain and use condoms effectively. Seventy percent of youth were highly confident of their ability to obtain condoms when they needed them in the Wave 1 survey. This increased to 84 percent in the Wave 2 survey. A sizeable increase is also observed for the efficacy index. Interestingly, females and younger youth report larger gains in perceived self-efficacy with regard to being able to obtain condoms when needed.

Levels of perceived self-efficacy with regard to effective use were considerably lower than perceived self-efficacy to obtain a condom at the time of the Wave 1 survey, but larger gains are observed between the two surveys both overall and for all subgroups of youth. Nevertheless, only 62 percent of respondents reported being very confident of being able to use a condom effectively in the Wave 2 survey, and sizeable differences by sex and age remain, with females and younger youth reporting substantially lower levels of self-efficacy than males and older youth.

\section{Behaviors}

Behaviors resulting in adverse reproductive health consequences among youth constitute the ultimate outcomes for this analysis. Behavioral outcomes were divided into two categories: (1) sexual initiation and reported sexual activity and (2) behavior associated with condom use.

Sexual behaviors: Four indicators were considered within the category of sexual initiation and reported activity outcomes: (1) the proportion of youth who had initiated sex, (2) the proportion of youth practicing secondary abstinence, (3) number of sexual partners in the last month, and (4) number of sexual partners in the last 12 months. Secondary abstinence was operationally defined as being sexually initiated but with no sexual partners in the previous 12 months. Data on changes in these indicators are displayed in Table 14.

The data indicate an increase in the proportion of sexually initiated youth from 45 percent to 67 percent. However, because the estimates are based upon the same individuals, who were two years older at the time of the Wave 2 survey, the observed increase in the proportion of youth who report being sexually experienced is not surprising. The increase was somewhat higher for males and 14 to 22 year-olds. The key question with regard to these data is whether the changes between the two surveys differed depending upon whether the youth had been exposed to life skills or not, a question addressed in the next section on page 43 . 
Table 14 Sexual behavior (in percentages)

\begin{tabular}{|c|c|c|c|c|c|c|c|c|c|c|c|c|c|c|c|c|}
\hline & \multirow{2}{*}{\multicolumn{2}{|c|}{ All youth }} & \multicolumn{4}{|c|}{ Gender } & \multicolumn{6}{|c|}{ Race } & \multicolumn{4}{|c|}{ Age group } \\
\hline & & & Fer & rale & & le & Afri & can & Ind & & Otr & ers & 14 & 18 & 19 & \\
\hline & Wave 1 & Wave 2 & Wave 1 & Wave 2 & Wave 1 & Wave 2 & Wave 1 & Wave 2 & Wave 1 & Wave 2 & Wave 1 & Wave 2 & Wave 1 & Wave 2 & Wave 1 & Wave 2 \\
\hline Sexually initiated & 44.7 & $66.8^{\star \star *}$ & 42.0 & $62.3^{* \star *}$ & 47.9 & $72.1^{* \star *}$ & 52.0 & $74.5^{\star \star *}$ & 17.8 & $38.1^{* * *}$ & 28.8 & $50.5^{\star *}$ & 28.8 & $56.1^{* * *}$ & 80.3 & $90.7^{\star \star \star}$ \\
\hline Sample size & 2,221 & 2,221 & 1,201 & 1,201 & 1,020 & 1,020 & 1,711 & 1,711 & 399 & 399 & 111 & 111 & 1,535 & 1,535 & 686 & 686 \\
\hline $\begin{array}{l}\text { Secondary } \\
\text { abstinence }\end{array}$ & 3.0 & $8.1^{* * *}$ & 1.6 & $8.5^{\star * \star}$ & 4.6 & $7.6^{*}$ & 2.9 & $8.1^{* * *}$ & 3.0 & 6.0 & 6.7 & 13.3 & 3.1 & $7.5^{\star \star}$ & 3.0 & $8.6^{* * *}$ \\
\hline $\begin{array}{l}>1 \text { partner in last } \\
\text { month }\end{array}$ & 9.4 & 10.5 & 1.8 & 2.5 & 17.7 & 19.0 & 9.7 & 11.3 & 7.0 & 3.3 & 4.0 & 0.0 & 10.1 & 12.1 & 8.9 & 9.1 \\
\hline $\begin{array}{l}>2 \text { partners in } \\
\text { last } 1 \text { year }\end{array}$ & 7.3 & $10.3^{*}$ & 0.8 & 2.2 & 14.4 & $19.0^{*}$ & 7.0 & $10.9^{* \star}$ & 12.3 & 4.5 & 3.3 & 6.7 & 6.9 & $13.2^{* *}$ & 7.6 & 8.0 \\
\hline Sample size & 955 & 955 & 490 & 490 & 465 & 465 & 856 & 856 & 68 & 68 & 31 & 31 & 417 & 417 & 538 & 538 \\
\hline
\end{tabular}

Statistical tests were done using fixed effect models to identify significant change between the two waves $\left({ }^{* * *} p<.001 ;{ }^{* *} p<.01 ;{ }^{*} p<.05\right)$

Age group for panel refers to age of adolescents during Wave 1. 
The data suggest a modest increase in the proportion of youth practicing secondary abstinence, particularly among females and Africans. There is little indication of significant changes in behavior with regard to number of sexual partners in the four weeks prior to the Wave 1 and 2 surveys. On average, approximately 9 to 10 percent of youth reported having more than one sexual partner in the month prior to both the Wave 1 and 2 surveys. Not surprisingly, males reported significantly higher levels of recent sexual activity than females. Differentials by race were modest in magnitude.

The data reveal a small, but statistically significant increase from ( 7 to 10 percent) in the proportion of youth who report having more than two partners in the 12 months prior to the survey. Inspection of subgroup estimates indicates that males, Africans, and younger youth bring about most of this change.

Condom use: Table 15 presents data on three indicators of behavior related to condom use: condom use at first sex, consistent condom use, and use at last sex. Consistent condom use was operationally defined as youth who reported that they always used condoms with each of the last three sexual partners during the last 12 months. Significant increases between the Wave 1 and 2 surveys are observed for all three indicators. With regard to condom use at first sex, the data indicate statistically significant increases of 10 to 12 percentage points for females, Africans, and younger youth. However, rates of condom use at first sex remain substantially lower among Africans than among youth in other racial groups. 
Table 15 Condom use (in percentage)

\begin{tabular}{|c|c|c|c|c|c|c|c|c|c|c|c|c|c|c|c|c|}
\hline & \multirow{2}{*}{\multicolumn{2}{|c|}{ All youth }} & \multicolumn{4}{|c|}{ Gender } & \multicolumn{6}{|c|}{ Race } & \multicolumn{4}{|c|}{ Age group } \\
\hline & & & Fen & ale & & & Afri & can & & & Oth & ers & & & & \\
\hline & Wave 1 & Wave 2 & Wave 1 & Wave 2 & Wave 1 & Wave 2 & Wave 1 & Wave 2 & Wave 1 & Wave 2 & Wave 1 & Wave 2 & Wave 1 & Wave 2 & Wave 1 & Wave 2 \\
\hline $\begin{array}{l}\text { Used condom } \\
\text { during first } \\
\operatorname{sex}(x)\end{array}$ & 39.2 & $49.1^{* *}$ & 38.5 & $50.0^{\star *}$ & 40.3 & 48.0 & 31.6 & $43.4^{* \star \star}$ & 70.8 & 74.8 & 76.4 & 70.4 & 37.6 & $48.1^{* \star}$ & 42.2 & $51.0^{*}$ \\
\hline Sample size & 696 & 863 & 418 & 494 & 278 & 369 & 569 & 700 & 72 & 119 & 55 & 44 & 452 & 563 & 244 & 300 \\
\hline $\begin{array}{l}\text { Consistent } \\
\text { condom use }\end{array}$ & 31.5 & $36.1^{*}$ & 21.7 & 24.3 & 42.3 & $49.1^{*}$ & 29.3 & $36.0^{\star \star}$ & 46.8 & 32.3 & 58.3 & 50.0 & 31.7 & $39.1^{*}$ & 31.3 & 33.8 \\
\hline $\begin{array}{l}\text { Used condom } \\
\text { during last sex }\end{array}$ & 46.5 & $52.7^{\star *}$ & 37.8 & 42.8 & 56.4 & $64.0^{\star}$ & 44.7 & $53.4^{* * *}$ & 59.7 & $41.9^{*}$ & 66.7 & 58.3 & 48.3 & $57.6^{\star *}$ & 45.1 & 48.9 \\
\hline Sample size & 955 & 955 & 490 & 490 & 465 & 465 & 856 & 856 & 68 & 68 & 31 & 31 & 417 & 417 & 538 & 538 \\
\hline
\end{tabular}

Statistical tests were done using fixed effect models to identify significant change between the two waves $\left({ }^{* \star *} p<.001 ;{ }^{* *} p<.01 ;{ }^{*} p<.05\right)$.

Age group for panel refers to age of adolescents during Wave 1.

(x) Estimated among those who were sexually initiated within 2 years prior to the surveys. 
Similar observations may be made with regard to consistent condom use and condom use at last sex. Results suggest statistically significant increases in both indicators. The largest increases in condom use are indicated among Africans, younger youth, and males. It is worth noting, however, that despite substantial increases in condom use, reported consistent use remains below 50 percent for most subgroups. It is important to note that while condom use at first sex may be lower among Africans as compared to other racial groups, consistent condom use and condom use at last sex are as high or higher among Africans.

\section{I mpact of Exposure to Life Skills Education on Outcome I ndicators}

This section presents estimates of the magnitude of impact of exposure to life skills education. In order to isolate the contribution of life skills education to the changes in outcome indicators reported in the previous section, it was necessary to account for changes in other factors that may have influenced these outcomes and the fact that exposure to life skills education was not implemented randomly. Indeed, the largest gains in exposure to life skills education were among precisely those subgroups of youth who had the lowest exposure levels to life skills instruction and higher prevalence of sexual risk-taking behaviors in the Wave 1 survey.

\section{Impact on knowledge, attitudes, and skills}

Table 16 presents estimates of the impact of exposure to life skills education on the knowledge and condom self-efficacy outcome variables. With regard to impact on correct knowledge of HIV transmission, the results show a significant positive influence of exposure to life skills education (i.e., toward improved knowledge). ${ }^{1}$ The coefficient for the survey year is also significant, indicating that other societal influences also contributed to improved levels of knowledge between the Wave 1 and 2 surveys. The significant effect for the survey year variable may be interpreted as reflecting the combined effects of maturation of youth, exposure to other sources of information regarding modes of HIV transmission other than life skills education, and general changes in society (often referred to as secular trends).

Exposure to life skills education also had a positive effect on awareness of STIs other than HIV/AIDS, particularly among males, Africans, and younger youth, although other factors also contributed to this change as reflected by the significant effect of the survey year variable.

With regard to knowledge of female STI symptoms, the exposure effects, while having positive signs, fail to achieve statistical significance at the 95 percent level of confidence. However, impact is observed among males and Africans. For knowledge of STI symptoms in males, a significant effect of exposure to life skills education is only observed among Africans. The significant effect

\footnotetext{
${ }^{1}$ That the effect was positive is indicated by the positive sign of the coefficients for the life skills exposure variable. A negative sign would indicate an inverse relationship between changes in exposure to life skills and changes in knowledge.
} 
Table 16 Fixed effect model coefficients showing the association between reproductive health knowledge and self-efficacy, with exposure to life skills, 1999 and 2001

\begin{tabular}{|c|c|c|c|c|c|c|c|c|c|c|c|c|c|c|c|c|}
\hline \multirow{3}{*}{$\begin{array}{l}\text { Knowledge/self } \\
\text { efficacy outcomes }\end{array}$} & \multirow[t]{3}{*}{ Effects } & \multirow[t]{3}{*}{ Model } & \multirow{2}{*}{\multicolumn{2}{|c|}{ All youth }} & \multicolumn{4}{|c|}{ Gender } & \multicolumn{4}{|c|}{ Race } & \multicolumn{4}{|c|}{ Age } \\
\hline & & & & & \multicolumn{2}{|c|}{ Female } & \multicolumn{2}{|c|}{ Male } & \multicolumn{2}{|c|}{ African } & \multicolumn{2}{|c|}{ Others } & \multicolumn{2}{|c|}{$14-18$} & \multicolumn{2}{|c|}{$19-22$} \\
\hline & & & Coef & $p$ value & Coef & $p$ value & Coef & $p$ value & Coef & $p$ value & Coef & $p$ value & Coef & $p$ value & Coef & $p$ value \\
\hline \multirow{2}{*}{$\begin{array}{l}\text { Correct knowledge of } \\
\text { HIV/AIDS transmission }\end{array}$} & Trend & OLS & 0.151 & $<0.001$ & 0.171 & $<0.001$ & 0.013 & $<0.001$ & 0.144 & $<0.001$ & 0.160 & 0.002 & 0.183 & $<0.001$ & 0.096 & 0.011 \\
\hline & Exposure & & 0.019 & $<0.001$ & 0.010 & 0.034 & 0.029 & $<0.001$ & 0.023 & $<0.001$ & 0.001 & 0.878 & 0.015 & 0.001 & 0.024 & 0.001 \\
\hline \multirow{2}{*}{$\begin{array}{l}\text { Knows of STI other } \\
\text { than HIV/AIDS }\end{array}$} & Trend & logit & 1.111 & $<0.001$ & 1.312 & $<0.001$ & 0.908 & $<0.001$ & 1.080 & $<0.001$ & 1.147 & $<0.001$ & 1.222 & $<0.001$ & 0.832 & $<0.001$ \\
\hline & Exposure & & 0.057 & $<0.001$ & 0.041 & 0.078 & 0.074 & 0.001 & 0.066 & $<0.001$ & 0.019 & 0.623 & 0.059 & 0.003 & 0.026 & 0.394 \\
\hline \multirow{2}{*}{$\begin{array}{l}\text { Women's STI } \\
\text { symptoms recalled }\end{array}$} & Trend & OLS & 0.261 & $<0.001$ & 0.258 & $<0.001$ & 0.243 & 0.001 & 0.283 & $<0.001$ & 0.140 & 0.233 & 0.319 & $<0.001$ & 0.196 & 0.015 \\
\hline & Exposure & & 0.016 & 0.072 & -0.005 & 0.661 & 0.042 & 0.001 & 0.026 & 0.010 & -0.025 & 0.209 & 0.003 & 0.770 & 0.031 & 0.031 \\
\hline \multirow{2}{*}{$\begin{array}{l}\text { Men's STI symptoms } \\
\text { recalled }\end{array}$} & Trend & OLS & 0.261 & $<0.001$ & 0.193 & 0.006 & 0.352 & $<0.001$ & 0.273 & $<0.001$ & 0.198 & 0.106 & 0.332 & $<0.001$ & 0.167 & 0.029 \\
\hline & Exposure & & 0.014 & 0.110 & 0.011 & 0.365 & 0.015 & 0.187 & 0.022 & 0.024 & -0.019 & 0.348 & 0.008 & 0.482 & 0.018 & 0.176 \\
\hline \multirow{2}{*}{$\begin{array}{l}\text { Ways to protect } \\
\text { against STI }\end{array}$} & Trend & OLS & 0.118 & $<0.001$ & 0.111 & 0.008 & 0.115 & 0.010 & 0.119 & $<0.001$ & 0.149 & 0.062 & 0.179 & $<0.001$ & 0.027 & 0.563 \\
\hline & Exposure & & 0.003 & 0.608 & -0.008 & 0.315 & 0.015 & 0.054 & 0.003 & 0.649 & -0.001 & 0.952 & 0.007 & 0.341 & -0.006 & 0.483 \\
\hline \multirow{2}{*}{$\begin{array}{l}\text { A girl can get pregnant } \\
\text { after having sex once }\end{array}$} & Trend & logit & 0.895 & $<0.001$ & 0.594 & $<0.001$ & 1.216 & $<0.001$ & 0.879 & $<0.001$ & 1.011 & 0.004 & 0.996 & $<0.001$ & 0.745 & 0.010 \\
\hline & Exposure & & 0.068 & 0.001 & 0.086 & 0.004 & 0.057 & 0.040 & 0.068 & 0.001 & 0.095 & 0.162 & 0.054 & 0.017 & 0.118 & 0.027 \\
\hline \multirow{2}{*}{$\begin{array}{l}\text { No. of modern } \\
\text { contraceptive methods } \\
\text { recalled }\end{array}$} & Trend & OLS & 0.254 & $<0.001$ & 0.213 & $<0.001$ & 0.300 & $<0.001$ & 0.243 & $<0.001$ & 0.301 & $<0.001$ & 0.309 & $<0.001$ & 0.116 & 0.005 \\
\hline & Exposure & & 0.019 & $<0.001$ & 0.004 & 0.450 & 0.036 & $<0.001$ & 0.021 & $<0.001$ & 0.013 & 0.201 & 0.019 & $<0.001$ & 0.007 & 0.359 \\
\hline \multirow{2}{*}{$\begin{array}{l}\text { Knows source of } \\
\text { condom }\end{array}$} & Trend & logit & 1.448 & $<0.001$ & 1.388 & $<0.001$ & 2.233 & 0.002 & 1.130 & $<0.001$ & UE & & 1.393 & $<0.001$ & 2.031 & 0.066 \\
\hline & Exposure & & 0.134 & 0.025 & 0.183 & 0.031 & -0.032 & 0.805 & 0.200 & 0.007 & UE & & 0.152 & 0.016 & -0.246 & 0.372 \\
\hline \multirow{2}{*}{$\begin{array}{l}\text { Confident in acquiring } \\
\text { condoms if needed }\end{array}$} & Trend & OLS & 0.256 & $<0.001$ & 0.421 & $<0.001$ & 0.063 & 0.024 & 0.248 & $<0.001$ & 0.285 & $<0.001$ & 0.319 & $<0.001$ & 0.146 & $<0.001$ \\
\hline & Exposure & & 0.010 & 0.013 & 0.016 & 0.006 & 0.003 & 0.498 & 0.010 & 0.025 & 0.010 & 0.195 & 0.003 & 0.576 & 0.017 & 0.009 \\
\hline \multirow{2}{*}{$\begin{array}{l}\text { Confident in using } \\
\text { condoms effectively }\end{array}$} & Trend & OLS & 0.386 & $<0.001$ & 0.412 & $<0.001$ & 0.358 & $<0.001$ & 0.413 & $<0.001$ & 0.247 & $<0.001$ & 0.416 & $<0.001$ & 0.330 & $<0.001$ \\
\hline & Exposure & & 0.016 & $<0.001$ & 0.021 & 0.001 & 0.011 & 0.052 & 0.017 & 0.001 & 0.007 & 0.416 & 0.013 & 0.009 & 0.020 & 0.019 \\
\hline
\end{tabular}

Age refers to age of respondents during wave 1 survey; all estimates are controlled for change in socioeconomic status of the respondents.

UE: Un-estimated due to lack of variance among the discordant pairs. 
of the survey year variable again indicates increased knowledge among youth in the study population attributable to other factors. There is no impact of exposure to life skills education on knowledge of ways to protect against STI transmission.

The data show an impact of exposure on knowledge that a girl can get pregnant as a result of having sex only once and on knowledge of modern methods of contraception for youth in the aggregate and for most sub-groups of youth.

Impact of exposure on knowledge of a source of condoms is observed among Africans, 14 to 18 year-olds, and in contrast to many previous outcomes, females. The latter result might reflect the fact that females were much less knowledgeable than males concerning where to obtain condoms at the time of the Wave 1 survey and thus were more likely to benefit from this component of life skills education.

With regard to confidence or perceived self-efficacy in obtaining and effectively using condoms, the data also suggest an impact of exposure to life skills education. For the confidence in being able to obtain a condom when needed outcome, impact appears to have been concentrated among females, Africans, and 19 to 22 year-olds. For the self-efficacy of condom use outcome, exposure effects appear to be widespread across subgroups of youth.

In sum, exposure to life skills education had a significant positive impact on the majority of the knowledge and condom self-efficacy outcome variables. However, other factors are also influencing these outcomes variables as evidenced by the significance of the survey year for all variables considered.

\section{Impact on behaviors}

Table 17 presents estimates of impact of exposure to life skills education on behaviors, including age at first sex, secondary abstinence, number of partners, and condom use.

For the analysis of age at first sex, only youth who reported not having been sexually initiated at the time of the Wave 1 survey are included in the analysis. ${ }^{2}$ Because the process of initiation of sex was censored or truncated by the Wave 2 survey, it was necessary to adopt a different statistical approach to estimate program impact. Instead of a fixed-effects model, a discrete logistic hazard model was used. This approach produces unbiased estimates with censored data, but does not address the problem of potential bias due to program targeting with respect to unobserved factors. To minimize bias due to program targeting, control variables for age, sex, race, residence (urban/rural), and household socioeconomic status were included in the model.

\footnotetext{
${ }^{2}$ Youth who were sexually initiated at the time of the Wave 1 survey were excluded from the analysis because this event pre-dated the implementation period of the life skills education being evaluated in this study.
} 
Table 17 Fixed effect model coefficients showing the association between sexual behavior and condom use with exposure to life skills, 1999 and 2001

\begin{tabular}{|c|c|c|c|c|c|c|c|c|c|c|c|c|c|c|c|c|}
\hline \multirow{3}{*}{$\begin{array}{l}\text { Sexual behavior/ } \\
\text { condom use }\end{array}$} & \multirow[t]{3}{*}{ Effects } & \multirow[t]{3}{*}{ Model } & \multirow{2}{*}{\multicolumn{2}{|c|}{ All }} & \multicolumn{4}{|c|}{ Gender } & \multicolumn{4}{|c|}{ Race } & \multicolumn{4}{|c|}{ Age } \\
\hline & & & & & \multicolumn{2}{|c|}{ Female } & \multicolumn{2}{|c|}{ Male } & \multicolumn{2}{|c|}{ African } & \multicolumn{2}{|c|}{ Others } & \multicolumn{2}{|c|}{$14-18$} & \multicolumn{2}{|c|}{$19-22$} \\
\hline & & & Coef & $p$ value & Coef & $p$ value & Coef & $p$ value & Coef & p value & Coef & $p$ value & Coef & $p$ value & Coef & $p$ value \\
\hline \multicolumn{17}{|l|}{ Sexual behavior } \\
\hline \multirow[t]{2}{*}{ Sexual initiation } & Trend & hazard & 0.017 & 0.790 & -0.012 & 0.884 & 0.077 & 0.389 & 0.049 & 0.487 & -0.275 & 0.070 & 0.022 & 0.796 & 0.021 & 0.816 \\
\hline & Exposure & & 0.009 & 0.224 & -0.014 & 0.167 & 0.029 & 0.007 & 0.006 & 0.446 & 0.032 & 0.021 & -0.001 & 0.936 & -0.003 & 0.782 \\
\hline \multirow{2}{*}{$\begin{array}{l}\text { Secondary } \\
\text { abstinence }\end{array}$} & Trend & logit & 1.303 & $<0.001$ & 2.099 & 0.001 & 0.795 & 0.036 & 1.248 & $<0.001$ & UE & & 1.426 & 0.009 & 1.317 & $<0.001$ \\
\hline & Exposure & & -0.055 & 0.274 & -0.035 & 0.754 & -0.053 & 0.341 & -0.073 & 0.167 & UE & & -0.030 & 0.654 & -0.076 & 0.349 \\
\hline \multirow{2}{*}{$\begin{array}{l}>2 \text { partners in } \\
\text { last } 12 \text { months }\end{array}$} & Trend & logit & 0.397 & 0.048 & 1.597 & 0.103 & 0.272 & 0.205 & 0.585 & 0.007 & UE & & 0.811 & 0.015 & 0.143 & 0.632 \\
\hline & Exposure & & 0.021 & 0.532 & 0.151 & 0.443 & 0.010 & 0.767 & 0.007 & 0.835 & UE & & -0.014 & 0.803 & 0.018 & 0.724 \\
\hline \multirow{2}{*}{$\begin{array}{l}>1 \text { partner in last } \\
1 \text { month }\end{array}$} & Trend & logit & 0.019 & 0.923 & -0.005 & 0.994 & -0.025 & 0.905 & 0.104 & 0.608 & UE & & 0.116 & 0.672 & -0.087 & 0.769 \\
\hline & Exposure & & -0.044 & 0.227 & -0.144 & 0.165 & -0.020 & 0.625 & -0.048 & 0.205 & UE & & -0.060 & 0.261 & -0.046 & 0.419 \\
\hline \multicolumn{17}{|l|}{ Condom use } \\
\hline \multirow{2}{*}{$\begin{array}{l}\text { Condom use } \\
\text { during first sex }\end{array}$} & Trend & logit & 0.420 & 0.001 & 0.469 & 0.004 & 0.421 & 0.050 & 0.500 & 0.001 & 0.211 & 0.477 & 0.528 & 0.001 & 0.239 & 0.278 \\
\hline & Exposure & & 0.039 & 0.001 & 0.043 & 0.006 & 0.040 & 0.080 & 0.048 & 0.000 & -0.007 & 0.826 & 0.036 & 0.044 & 0.035 & 0.115 \\
\hline \multirow{2}{*}{$\begin{array}{l}\text { Always used } \\
\text { condoms }\end{array}$} & Trend & logit & 0.241 & 0.070 & 0.170 & 0.373 & 0.298 & 0.110 & 0.336 & 0.015 & -1.366 & 0.084 & 0.375 & 0.054 & 0.158 & 0.407 \\
\hline & Exposure & & 0.040 & 0.095 & 0.044 & 0.188 & 0.036 & 0.300 & 0.033 & 0.196 & -0.055 & 0.653 & 0.011 & 0.760 & 0.062 & 0.078 \\
\hline \multirow{2}{*}{$\begin{array}{l}\text { Condom use } \\
\text { during last sex }\end{array}$} & Trend & logit & 0.397 & 0.003 & 0.292 & 0.090 & 0.518 & 0.014 & 0.505 & 0.000 & -1.727 & 0.039 & 0.683 & 0.001 & 0.178 & 0.321 \\
\hline & Exposure & & 0.046 & 0.045 & 0.045 & 0.120 & 0.051 & 0.201 & 0.047 & 0.049 & -0.157 & 0.256 & 0.046 & 0.220 & 0.037 & 0.226 \\
\hline
\end{tabular}

Except for sexual initiation and condom use during first sex, all estimates were done using fixed effect models, which included socioeconomic status as a control variable. Age refers to age of respondents during wave 1 survey.

UE: Un-estimated due to lack of variance among the discordant pairs.

The hazard and logit models used for sexual initiation and condom use during first sex controlled for age, sex, race, place of residence and socioeconomic status. 
As can be observed in Table 17, exposure effects on the probability of sexual initiation were not found overall. However, exposure to life skills education is associated with an increase in age at sexual initiation for males and for those in the "other" racial group.

With regard to the impact of life skills education on the prevalence of sexual abstinence, we found no significant effects. However, the survey year effect was significant and positive; suggesting that the increased prevalence of secondary abstinence observed at the bivariate level was due to influences other than exposure to life skills education.

Exposure to life skills education did not show any impact on the number of sexual partners (greater than two) in the preceding 12 months and on the number of sexual partners (greater than one) in the preceding month. However, the survey year variable was significant for those who reported more than two partners in the past 12 months overall, and particularly for Africans and youth aged 14 to 18 .

The bottom half of Table 17 presents the results of the impact of exposure to life skills education on the condom use variables: condom use at first sex, always use condoms, and condom use at last sex.

With regard to condom use at first sex, only youth who were not sexually initiated at the time of the Wave 1 survey were included in the analysis. The regression estimates indicate significant exposure effects for youth in the aggregate and for most of the subgroups of youth, but is particularly strong for females, Africans and youth aged 14 to 18.

The impact of exposure to life skills education was only marginally significant $(\mathrm{p}<.10)$ for the consistent condom use (i.e., with all partners) outcome variable. With regard to condom use at last sex, significant effects of life skills are observed overall and among Africans. In addition, the survey year variable was significant for all subgroups, suggesting that changes other societal factors are also contributing to changes in consistent condom use.

\section{Simulation results}

Since the models are non-linear, the magnitude of program effects cannot be easily assessed by looking at the regression coefficients. To provide readers with an appreciation of the magnitude of effects observed in the study, a series of "policy simulations" were run. Figure 4 displays the simulation results in graphical form for all outcomes for which significant program effects were observed overall and for each of the subgroups. In the simulations, the "observed" changes in the knowledge and behavior outcomes were compared to two hypothetical scenarios: one where none of the youth were exposed to life skills education and a second where all of the youth were exposed to all of the topics (this represents the maximum potential impact of life skills education). By comparing the actual levels to the two hypothetical levels (none and all) we can see the magnitude of the impact of exposure to life skills education. 


\section{Hgrizons}

As may be observed, the magnitude of program impact is, while statistically significant, generally modest. However, predicted levels of outcomes under the hypothetical scenario of maximum increases in program exposure indicate the potential for substantial impact once life skills education becomes fully implemented. For example, the simulation estimates in Figure 4 suggest that if life skills education had been fully implemented by 2001 (i.e., all students had been exposed to all 11 life skills topics in the 2001 school year), condom use at first sex would have been 5 percentage points higher ( 49 vs. 44 percent), and condom use during last sex would have been 8 percentage points higher (64 vs. 56 percent) as compared to the observed levels.

Figure 4 Simulation of the impact of number of life skills on selected outcomes among all respondents

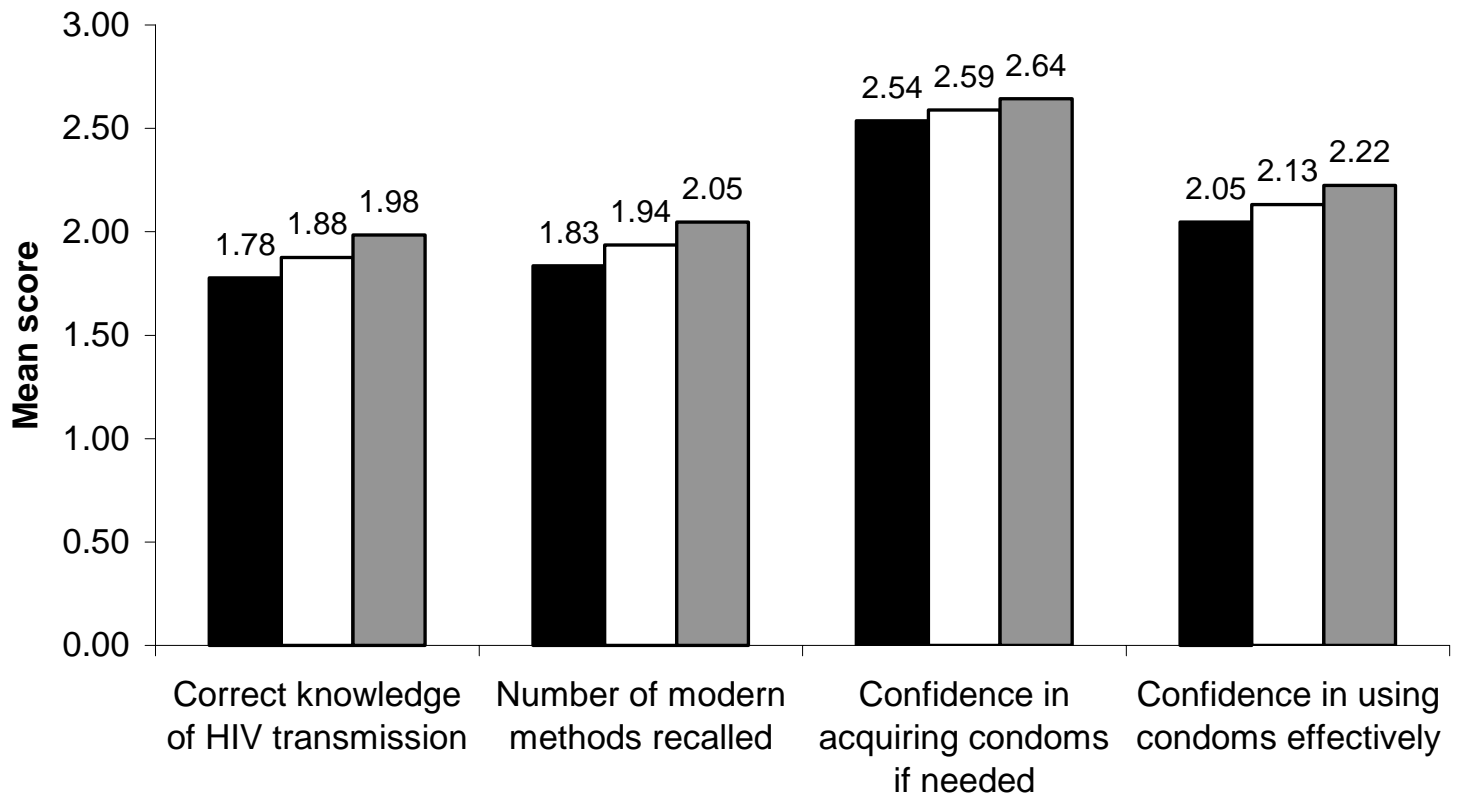

- No exposure $\quad \square$ Mean exposure $\quad \square$ Maximum exposure 


\section{Discussion}

The data reviewed in this report suggests that some progress has been made in students' exposure to life skills education in KZN. By 2001, most secondary school students in Durban Metro and Mtunzini Districts were exposed to information that can help them reduce their risk of exposure to HIV/STIs and pregnancy and offer compassion and care to people living with HIV/AIDS. This is a substantial increase since 1999. The most substantial expansion in exposure to life skills education was found among African students.

The evidence concerning changes in outcome indicators is mixed in nature. With regard to improvements in sexual and reproductive health-related knowledge, gains were generally modest in magnitude and uneven across the topics considered. However, substantial gains were noted on a number of key topics for HIV prevention and perceived self-efficacy with regard to condom procurement and use. The largest gains were observed among Africans and younger youth.

With regard to behaviors, larger changes are seen in condom use than for other sexual behaviors. The data suggest a modest increase in the proportion of youth practicing secondary abstinence, yet also a small, but statistically significant increase in the proportion of youth who report having more than two partners in the 12 months prior to the survey. Sizeable and consistent increases in condom use were noted more or less across all subgroups of youth.

The impact evaluation findings are on the whole encouraging, indicating that exposure to life skills education has an effect on selected areas of sexual and reproductive health knowledge, self-efficacy concerning condoms, and reported condom use. However, the impacts were generally modest, and despite increases in sexual and reproductive health knowledge, the depth of knowledge among KZN youth remains thin. The failure to observe broader impact on sexual behaviors is of concern since increased age at first sex and reduction in numbers of sexual partners appear to have contributed to the declines in HIV infection rates among youth in Uganda (Kilian et al. 1999; Fabiani et al. 2001).

Significant effects of life skills education were more frequently observed among younger youth, Africans, and males than older youth, non-Africans and females. That younger youth appear to have been more influenced by exposure to life skills education is important, as youth in this age range received higher doses of exposure to the program than older youth, many of whom attended school only part of the time during the study period. The greater response among African youth might reflect, despite efforts to control for program targeting, the fact that life skills education during the study period focused on schools that were previously underserved, many of which had predominantly African student bodies. Alternatively, life skills education may play a more important role in the lives of African youth, perhaps providing a source of information and support found less frequently in their social environments than for other youth. The observation of more significant impact on males is of interest because of the important role that male youth can play in curbing the HIV/AIDS epidemic in South Africa. 


\section{Hgrizons}

Finally, several limitations of this evaluation need to be reiterated. First, the observation period for the present study was short-two years. This, combined with the fact that life skills education had been implemented unevenly in the schools, means that the impact estimates should be interpreted with caution. Continued evaluation of exposure to life skills education needs to be undertaken in order to obtain a fuller appreciation of its impact. It is necessary to assess the medium- to long-term impact of program exposure, as a number of studies of school-based interventions in developing country settings have found that impacts tend to be short-term or transitory in nature (Speizer et al. 2003). Second, there are several limitations to the approach used to measure exposure to life skills education in the study. Exposure in this study is based on student recall of the 11 life skills topics. Using recall as a proxy for exposure could result in an underestimate of true exposure if students did not remember learning about specific topics or an overestimate if they reported learning something through school-based life skills education, which they in fact may have heard about through another source. Unfortunately no objective measures of exposure were collected to ascertain the amount of bias. In addition, the indicators used pertain to coverage or the quantity of life skills education offered, but do not measure the quality of the education. Given that teachers are often reluctant to take on discussing sensitive topics with students, it is by no means certain that the implementation of life skills education in the schools included in the study followed the protocols set out by the national or provincial Ministry of Education. Measuring this would require observation in classrooms, an exercise for which the present study lacked sufficient resources. 


\section{Programmatic I mplications}

The results of this study have a number of implications for the provision of life skills education in South Africa.

- Knowledge of reproductive health/STIs/HIV is generally good, but could be improved. While almost all respondents were aware of sexual transmission and modes of prevention, many gaps in knowledge remain. In particular, there is a lack of knowledge that HIV can be transmitted by sharing needles and other unclean instruments, and from mother to child during pregnancy, labor, and delivery.

- Life skills education should equally emphasize all methods of preventing pregnancy and transmission of STIs and HIV. The results of this study suggest that students who are exposed to life skills education have increased their use of condoms, but there was no impact of exposure on other sexual behaviors such as abstinence and number of partners. While it is possible that the condom use messages are the only ones that students retained, it is also possible that life skills education is focusing on condom use and less on other means of preventing pregnancy, STIs, and HIV.

- Life skills education should support secondary abstinence, which is already changing due to other factors. The results show that secondary abstinence has increased during the study time period. However, this change was not attributable to exposure to life skills education. Clearly youth view secondary abstinence as an important option and this behavior should be supported through the life skills program.

- The gap in exposure to life skills education among the different racial groups needs to be further narrowed. In particular, life skills education for black populations needs to be strengthened. While this study shows significant improvement in this area over the two years of the study, the gap persists.

- Life skills education should focus on younger youth. The results showed stronger effects among younger youth as compared to older youth, suggesting that life skills education should move more towards younger ages. Alternative strategies may be needed for older youth, such as out-of-school programs.

- Females have high knowledge, but are unable to act on that knowledge. While female respondents had high knowledge levels of sexual transmission and prevention due to life skills, they showed relatively minor improvements in behavior. Life skills education should focus on skills to overcome barriers to sexual behavior change.

- Strengthen sexual behavior change among males. The significant impact of life skills on condom use and other variables among males is important and should be further strengthened given the key role that male youth can play in curbing the HIV/AIDS epidemic in South Africa. 


\section{Hgrizons}

\section{References}

Blanc, Ann K. and Ann A. Way. 1998. "Sexual behavior, contraceptive knowledge and use," Studies in Family Planning 29(2): 106-116.

Boler, T. 2003. The Sound of Silence. London: ActionAID.

Bollen, K., D. Guilkey, and T. Mroz. 1995. "Binary outcomes and endogenous explanatory variables: Tests and solutions with an application to the demand for contraceptive use in Tunisia," Demography, 32(1): 111-131.

Bongaarts, John and Barney Cohen. 1998. "Introduction and overview," Studies in Family Planning 29(2): 99-105.

Brown, Lisanne et al. 2001. "Measuring community effects on adolescent reproductive health in KwaZulu Natal, South Africa," presented at the annual meetings of the Population Association of America, Washington, D.C., 26-28 March.

Brown, Lisanne et al. 2003. "Secondary School Principals Report Dramatic Expansion of Life Skills," Horizons Research Summary. Washington, D.C.: Population Council.

Caldwell, John C. et al. 1998. "The construction of adolescence in a changing world," Studies in Family Planning 29(2): 137-153.

Central Statistical Service. 1997. "Census '96: Preliminary Estimates of the Size of the Population of South Africa." Pretoria: Central Statistics.

Children's Rights' Charter of South Africa. 1992.

Department of Health (South Africa). 2002. "National HIV and Syphilis Sero-Prevalence Survey of Women Attending Public Antenatal Clinics in South Africa: Summary Report." Pretoria: DOH (Available at: http://www.doh.gov.za/aids/docs/syphilis.html).

Department of Health and Department of Education (South Africa). 1998. "Life Skills and HIV/AIDS Education Programme.” DOH/DOE Project Report. Pretoria.

DiCenso, A. et al. 2002. "Interventions to reduce unintended pregnancies among adolescents: Systematic review of randomised controlled trials," British Medical Journal 321:1426-1435.

Fabiani, M. S. et al. 2001. "Trend in HIV-1 prevalence in an antenatal clinic in north Uganda and adjusted rates for the general female population," AIDS 15: 97-103. 
FOCUS on Young Adults. 2001. Advancing Young Adult Reproductive Health: Actions for the Next Decade. Washington, D.C.: FOCUS on Young Adults.

Kaufman, Carol E. 1997. "Reproductive control in South Africa." Policy Research Division, Working Paper No. 97. New York: Population Council.

Kilian, A.H.D. et al. 1999. "Reductions in Risk Behaviour Provide the Most Consistent Explanation for Declining HIV-1 Prevalence in Uganda," AIDS 13: 391-398.

Kirby, D. 1999. Looking for Reasons Why: Antecedents of Adolescent Sexual Risk Taking, Pregnancy and Childbearing: Implications for Research and Programs. Washington, D.C.: National Campaign to Prevent Teen Pregnancy.

.2001. Emerging Answers: Research Findings on Programs to Reduce Sexual Risk-Taking

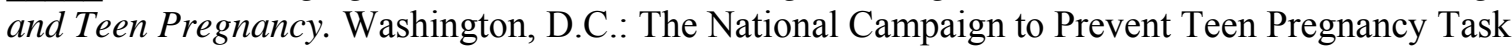
Force on Effective Programs and Research.

Mandela Foundation and HSRC. 2003. South African National HIV Prevalence, Behavioural Risks and Mass Media: Household Survey 2002. Cape Town: Human Sciences Research Council.

Mazur, Robert E. 1995. Population Structure, Fertility and Childhood Mortality in South Africa: Lessons to be Learned from Analysis of the Poverty Survey. Tygerburg, South Africa: Centre for Epidemiological Research in Southern Africa, South African Medical Research Council.

Mensch, Barbara, Judith Bruce, and Margaret E. Greene. 1998. "The uncharted passage: Girls' adolescence in the developing world." New York: Population Council.

Moote, G.T. and J.S. Wodarski. 1997. "The acquisition of Life Skills through adventure-based activities and programs - A review of the literature," Adolescence. 32(125):143-67.

MRC and MACRO International. 1998. The 1998 South Africa Demographic and Health Survey (SADHS).

National Education Conference. 1992. "Report on the proceedings of the National education Conference,” Broederstroom: March 1992.

Pan American Health Organization. 2001. Life Skills Approach to Child and Adolescent Healthy Human Development. Washington, D.C.: PAHO.

Richter, L.M. 1996. "A survey of reproductive health issues among urban black youth in South Africa." A final report to the Society for Family Health - South Africa

Rutenberg, Naomi et al. 2001. "Transitions to Adulthood in the Context of AIDS in South Africa: Report of Wave I," Horizons Midterm Report. Washington, D.C.: Population Council. 


\section{Hgrizons}

Rutenberg, Naomi et al. 2002. "Pregnant or positive: Adolescent childbearing and HIV risk in South Africa." Policy Research Division Working Paper Series No. 162. New York: Population Council. Under review at Studies in Family Planning.

Speizer, I.S., R.J. Magnani, and C.E. Colvin. In press. "The Effectiveness of Adolescent Reproductive Health Interventions in Developing Countries: A Review of the Evidence," Journal of Adolescent Health.

South Africa Department of Health and South Africa Department of Education, 1997/98. Life Skills and HIV/AIDS Education Programme: Project Report.

South African Department of Health. 2002. "National HIV and Syphilis Sero-Prevalence Survey of Women Attending Public Antenatal Clinics in South Africa: Summary Report." Available at: http://www.doh.gov.za/aids/docs/syphilis.html. (downloaded 6/24/02).

Thompson, L. 1990. A History of South Africa. Yale University Press, New Haven.

Thomson, G.H. 1951. The Factor Analysis of Human Ability. London: University of London Press.

Turner, AG, R.J. Magnani, M. Shuaib.1996. "A not quite as quick alternative to the expanded programme on immunization (EPI) cluster survey design," International Journal of Epidemiology 25: 198-203.

UNICEF/EASARO. 1996. Life Skills education - planning for research. MNH/PSF/96.2 REV 1.

UNICEF, UNAIDS, and WHO. 2002. Young People And HIV/AIDS: Opportunity in Crisis. Geneva.

Varga, C. 1997. "Sexual decision-making and negotiations in the midst of AIDS: Youth in KwaZulu-Natal," Health Transition Review 7(2):13-41.

Wilson, F and M. Ramphele. 1989. Uprooting poverty: The South African Challenge. David Philip: Cape Town.

Zabin, Laurie and Karungari Kiragu. 1998. "Health consequences of adolescent sexuality and fertility behavior in sub-Saharan Africa," Studies in Family Planning (29)2: 210-232. 


\section{Appendix A}

Two econometric approaches were used to address this potential bias. First, a fixed-effects estimator that took advantage of the panel data available to the study was used to estimate the impact of changes in life skills education implementation during the 1999-2001 period. Under this approach, changes in outcomes $(C)$ are regressed against changes in exposure to life skills $(P)$ and individual - $(X)$, household - $(Y)$ and community - $(Z)$ level factors (see equation 1). Subscripts "1" and " 2 " indicate survey wave.

$$
C_{i j 2}-C_{i j 1}=B_{1}\left(X_{i j 2}-X_{i j 1}\right)+B_{2}\left(Y_{i j 2}-Y_{i j 1}\right)+B_{3}\left(Z_{j 2}-Z_{j 1}\right)+B_{4}\left(P_{i j 2}-P_{i j 1}\right)+\left(\ni_{i j 2}-\ni_{i j 1}\right)(1)
$$

Because they do not vary over time, fixed unobserved factors, some of which are correlated with both program exposure and the outcome(s) of interest, are "differenced out" and the coefficient estimates of $B_{4}$, reflecting the impact of exposure to life skills, are unbiased. ${ }^{3}$ The influences of time-varying unobserved factors are not accounted for directly in the fixed effects model, but the aggregate influences of such factors can be accounted for by including a time or survey wave dummy variable. Depending upon the measurement scale of the outcome variable, logit, or ordinary least squares (OLS) fixed-effects models were used to estimate the effects of program exposure. Discrete hazard models were estimated for censored behavioral outcomes (e.g., sexual initiation).

Exposure to life skills education was measured as a continuous variable (range 0-11) indicating the total number of relevant topics covered in school as reported (independently) by school principals and youth for the 1999 and 2001 school years, respectively. ${ }^{3}$ Youth who had not attended school in a given school year were assigned a score of zero reflecting the fact that, although they may well have acquired relevant information and skills from other sources, they did not do so from school life skills education initiatives. Youth instead of principals' reports of life skills exposure were used in the analyses on the grounds that exposure not recalled is unlikely to have influenced behavior. ${ }^{4}$ Separate estimates of impact for key sub-groups of youth [gender, race (African, Indian, Other) and age (14-18 and 19-22)] were obtained by estimating separate models for each group. ${ }^{5}$ The following factors were also considered as independent variables: age, race (African, Indian, Other), gender, socioeconomic status and residence (urban/rural). In addition, various control variables were tested but did not influence the main findings. These included: in-school/out of school status, the change in whether a household had experienced a shock in the past 12 months (death,

\footnotetext{
${ }^{3}$ The 11 sexual-reproductive health-related life skills were: drugs and alcohol; STI transmission, symptoms and prevention; HIV transmission and prevention; caring for people with AIDS; violence and sexual abuse; relationships-negotiation and assertiveness; contraception; human growth and development; reproductive biology; sexual relations with the opposite sex; and self-esteem.

${ }^{4}$ Based upon the research literature, youth are likely to understate the actual quantity of life skills education offered due to absences from school and recall error. Principals, on the other hand, often overstate program implementation performance.

${ }^{5}$ Age here refers to age at the time of the Wave 1 survey.
} 


\section{Hgrizons}

unemployment, divorce, etc.), change in the number of adults in the household, change in the head of household, and change in parent/s living in household.

A second, "instrumental variables" or two stage least squares approach was used in the study to estimate the cumulative impact of life skills exposure. The model has two equations: a programme exposure equation (2) and an outcome equation (3), where $\mathrm{P}_{\mathrm{ij}}$ represents cumulative exposure over the two-year period of observation, $\varepsilon_{1 \mathrm{ij}}$ and $\varepsilon_{2 \mathrm{ij}}$ are error terms, and all other terms are as defined above in connection with equation (1). The outcome measure, cumulative exposure, had a range of $0-22$, reflecting the number of topics to which youth reported having been covered in one or more school classes.

$P_{i j}=B_{1} X_{i j}+B_{2} Y_{i j}+B_{3} Z_{j}+\ni_{l i j}(2)$

$C_{i j}=B_{4} X_{i j}+B_{5} Y_{i j}+B_{6} Z_{j}+B_{7} P_{i j}+\ni_{2 i j}(3)$

Bias is present to the extent that $\ni_{1 \mathrm{ij}}$ and $\jmath_{2 \mathrm{ij}}$ are correlated. To remove this, a two-step estimation procedure was used in which equation (2) was estimated and the resulting coefficient estimates used to predict the level of exposure for each study subject. The predicted level of exposure for each subject was then included in equation (3) as an independent variable. In order to statistically "identify" the model, at least one "instrumental" variable is needed in equation 2 that is not included in equation 3. An instrumental variable is one that theoretically influences an outcome of interest only indirectly, via, in this case, its effect on life skills exposure. As exposure to life skills education is influenced by both (1) school attendance and (2) the quantity and quality of efforts by the school, we included two or more instruments to ensure that the models are properly identified. Specification tests were carried out for all instrumental variables considered. Four instruments met these criteria: (1) whether head of household was a biological parent, (2) whether head of household was female, (3) number of adults living in the house, and (4) whether there was a death in the family during the period between the surveys.

The results show that the majority of the coefficients are of a similar magnitude and in the same direction as the results from the fixed effects estimation. The major difference is that the impact of exposure to life skills on the practice of secondary abstinence is larger statistically significant across several sub groups in our study. 


\section{Hgrizons}

Horizons is a global operations research program designed to:

- Identify and test potential strategies to improve HIV/AIDS prevention, care, and support programs and service delivery.

- Disseminate best practices and utilize findings with a view toward scaling up successful interventions.

\section{(2) Population Council}

Horizons is implemented by the Population Council in collaboration with

- International Center for Research on Women (ICRW)

- International HIV/AIDS Alliance

- Program for Appropriate Technology in Health (PATH)

- Tulane University

- Family Health International (FHI)

- Johns Hopkins University

For more information, please contact:

Horizons Program, Communications Unit 4301 Connecticut Avenue, NW Suite 280 Washington, DC 20008 USA

Tel: 202-237-9400

Fax: 202-237-8410

Email: horizons@pcdc.org www.popcouncil.org/horizons 